\title{
IMPACTOS AMBIENTALES DE LA OCUPACIÓN DEL SUELO POR EL DESARROLLO TURÍSTICO EN CAYO SANTA MARÍA (VILLA CLARA, CUBA)
}

\author{
Mario Burgui Burgui. Estudiante de Maestría en Medio Ambiente y Desarrollo. \\ Centro de Estudios de Medio Ambiente. Universidad de La Habana (Cuba). \\ Correo electrónico: marioburgui@yahoo.es
}

Recibido: 20 de noviembre de 2010. Aceptado: 10 de diciembre de 2010.

\begin{abstract}
RESUMEN
En este trabajo se realizó un análisis de la ocupación del suelo por el desarrollo turístico en Cayo Santa María, enfocado a evaluar cómo está afectando a la sostenibilidad de los paisajes naturales del cayo. Para ello, en primer lugar se describieron los componentes naturales y socio-económicos del cayo, y se identificaron las unidades de paisajes naturales. Posteriormente, se realizó una valoración de las unidades para su conservación, obteniendo las de la mitad este del cayo un valor más alto. También se valoraron los impactos ambientales actuales y previstos, según la ocupación del suelo por parcelas hoteleras, viales y otras infraestructuras. Los mayores impactos hasta la actualidad han tenido lugar en la mitad oeste del cayo, aunque se prevé que la parte oriental también sufra graves impactos al final de la etapa constructiva. Estas valoraciones se integraron para estimar la afección a la sostenibilidad de las unidades de paisajes naturales en la etapa actual, que en general se puede calificar de 'moderada'. Sin embargo, también se realizó una predicción de la afección que sufrirán si se aplica el plan de desarrollo previsto, en cuyo caso se prevé una afección 'alta'. Finalmente, se propusieron medidas para reducir dichas afecciones.
\end{abstract}

Palabras clave: Turismo, impacto ambiental, sostenibilidad, Geografía de los Paisajes.

\begin{abstract}
The aim of the study was to analyse how the soil occupation by tourism development is affecting the sustainability of Santa María Key's natural landscapes. For that purpose, the natural, social and economic components of the key were described and the natural landscape units were identified. After that, a valuation of the units' conservation values was made, resulting the east ones with a higher value. The environmental impacts of the soil occupation by hotels, roads and other infrastructures were also measured and valued. Most of these impacts had occurred in the west area, although serious impacts are also predicted in the east at the end of the building phase. All this information was fitted to measure how the sustainability of the landscape units was affected. In the present phase, it could be described as a 'moderate' affectation. Nevertheless, a prediction for the next phase was made too, resulting then as a 'high' affectation. Finally, measures were suggested in order to reduce these affectations.
\end{abstract}

Key words: Tourism, Environmental Impact, Sustainability, Landscape Geography. 


\section{INTRODUCCIÓN ${ }^{1}$}

La Cayería Norte de la provincia de Villa Clara (Cuba) es un polo turístico cuya importancia no ha dejado de crecer en los últimos años. La riqueza natural y el atractivo de la zona han concentrado importantes focos inversionistas. Entre todos los cayos destaca Cayo Santa María, un territorio con una peculiar forma alargada y estrecha separado en línea recta de Cuba por unos $28 \mathrm{~km}$. Su ordenamiento territorial ya ha sido establecido, pero el uso turístico actual está fundamentalmente desarrollado en la mitad oeste del cayo, dedicado al denominado 'turismo de sol y playa'.

La parte oriental de Cayo Santa María no ha sufrido aún un desarrollo de la actividad turística tan pronunciado. Pero ocurre que además esta es la zona del cayo con mayor riqueza natural y paisajística, por lo que es de máxima importancia tender hacia un modelo de desarrollo turístico compatible con la conservación de los recursos naturales y la funcionalidad de los paisajes. En este sentido, el análisis de la ocupación del suelo por las infraestructuras turísticas, la evaluación de los impactos ambientales asociados y las propuestas de medidas suponen un paso importante para la consecución de dicho modelo de desarrollo.

\section{OBJETIVOS DE LA INVESTIGACIÓN}

\section{Objetivo general}

Determinar cómo los impactos ambientales de la ocupación del suelo por el desarrollo turístico están afectando a la sostenibilidad de los paisajes naturales de Cayo Santa María.

\section{Objetivos específicos}

1. Conocer los componentes naturales y socio-económicos del cayo.

2. Delimitar, caracterizar y analizar las unidades de paisajes naturales.

3. Valorar las unidades de paisaje para su conservación.

4. Determinar y valorar los impactos ambientales de la ocupación del suelo por el desarrollo turístico sobre las unidades de paisaje.

5. Valorar las afecciones a la sostenibilidad de las unidades de paisaje.

6. Proponer medidas para reducir dichas afecciones.

\section{METODOLOGÍA DE LA INVESTIGACIÓN}

\section{Esquema general de la investigación}

La presente investigación estuvo compuesta de tres etapas básicas: a) Recopilación de información, análisis y descripción del área de estudio; b) Delimitación, caracterización y análisis de las unidades de paisajes naturales; c) Diagnóstico integrado y propuestas. En la Figura 1 se detallan los pasos seguidos en el estudio.

\footnotetext{
${ }^{1}$ Al final del artículo se encuentra un pequeño glosario donde puede consultarse el significado de algunos de los términos utilizados en este estudio.
} 
Figura 1. Esquema general de la investigación.

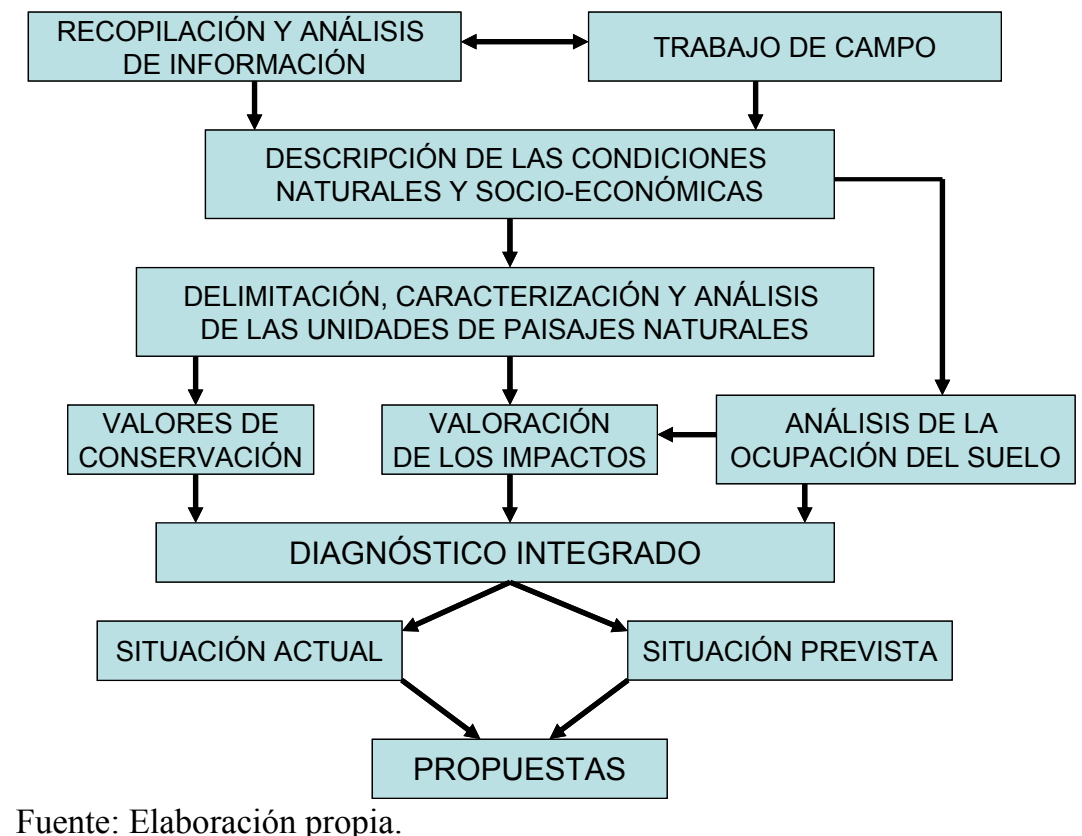

\section{Estructura del Diagnóstico Integrado}

El diagnóstico consistió en una valoración de las unidades para su conservación, una valoración de los impactos ambientales sobre estas unidades y posteriormente la integración de ambas valoraciones para estimar la afección a la sostenibilidad de las unidades de paisaje.

En el primer caso, se escogieron los siguientes criterios (Figura 2): estabilidad interna de los paisajes naturales, probabilidad de inundación, biodiversidad, áreas de mayor importancia ecológica, potencial ecoturístico, grado de conservación de las unidades de paisaje y factibilidad constructiva en función del sustrato geológico.

Para la valoración de los impactos, los criterios escogidos fueron: fragmentación de las unidades de paisaje, pérdida de hábitat natural en las unidades, pérdida de calidad estética, afecciones a la biodiversidad, alteraciones de las áreas de mayor importancia ecológica y contaminación.

Figura 2. Esquema de los pasos seguidos en el Diagnóstico Integrado

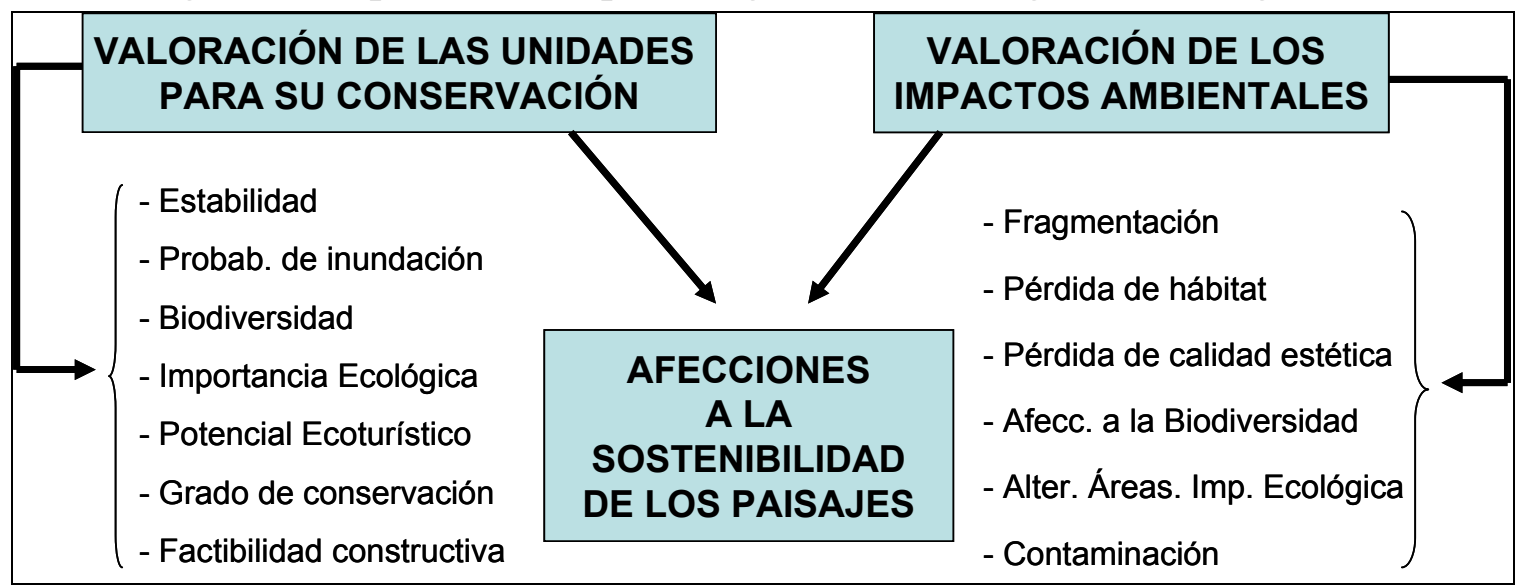

Fuente: Elaboración propia. 


\section{Metodología para la valoración}

Tanto para la valoración de las unidades de paisaje para su conservación, como para la valoración de los impactos ambientales, se utilizaron tablas de doble entrada, asignando un valor de 1 a 5 (y el 0 en su caso) a cada factor analizado. Posteriormente, se calculó el promedio para cada unidad, cuyo redondeo dio como resultado la valoración final (Cuadro 1). Los impactos se consideraron acumulativos entre una etapa y la siguiente.

Cuadro 1. Método para la realización de las valoraciones.

\begin{tabular}{|c|c|c|c|c|c|c|c|c|}
\hline Enidad & 1 & 2 & 3 & 4 & 5 & 6 & 7 & Total \\
\hline I & $V_{I 1}$ & $V_{I 2}$ & $V_{I 3}$ & $V_{I i}$ & $\ldots$ & $\ldots$ & $V_{I j}$ & Media $V_{I i-j}$ \\
\hline II & $V_{\text {II } 1}$ & $\mathrm{~V}_{\mathrm{II} 2}$ & $\mathrm{~V}_{\text {II } 3}$ & $V_{I I i}$ & $\ldots$ & & & Media $V_{\text {II } \mathrm{i}-\mathrm{i}}$ \\
\hline III & $V_{\text {III } 1}$ & $\mathrm{~V}_{\mathrm{III} 2}$ & $V_{\text {III3 }}$ & $\ldots$ & $\ldots$ & & & Media $V_{\text {III } i-j}$ \\
\hline
\end{tabular}

Fuente: Yeras (2005). Elaboración propia.

\section{DESCRIPCIÓN DEL ÁREA DE ESTUDIO}

\section{Localización y descripción general}

Cayo Santa María se localiza en la porción oeste del Subarchipiélago Camagüey, a su vez incluido dentro del Archipiélago Sabana-Camagüey. Administrativamente, el cayo pertenece a la provincia de Villa Clara, situándose al noreste de la misma en los límites con la provincia de Ciego de Ávila, a unos $28 \mathrm{~km}$ en línea recta de la isla de Cuba. Tiene 13,5 km de largo y el ancho máximo de la zona firme es de 1,6 km (Triana et al., 1998). Su área total aproximada es de $21,4 \mathrm{~km}^{2}$ (Arias, 2009). Se trata de un cayo único por su especial forma alargada, con gran belleza paisajística, una rica biodiversidad y playas de gran calidad.

\section{Condiciones naturales de formación de los paisajes}

Se estudiaron las condiciones naturales del cayo, haciendo especial hincapié en aquellas que se consideran formadoras de los paisajes naturales: estratigrafía, tipos de relieve, suelos y vegetación. Esta información se trató mediante los programas informáticos MapInfo 8.5, ArcView 3.2 y ArcMap 9.3, obteniendo los resultados que se muestran a continuación.

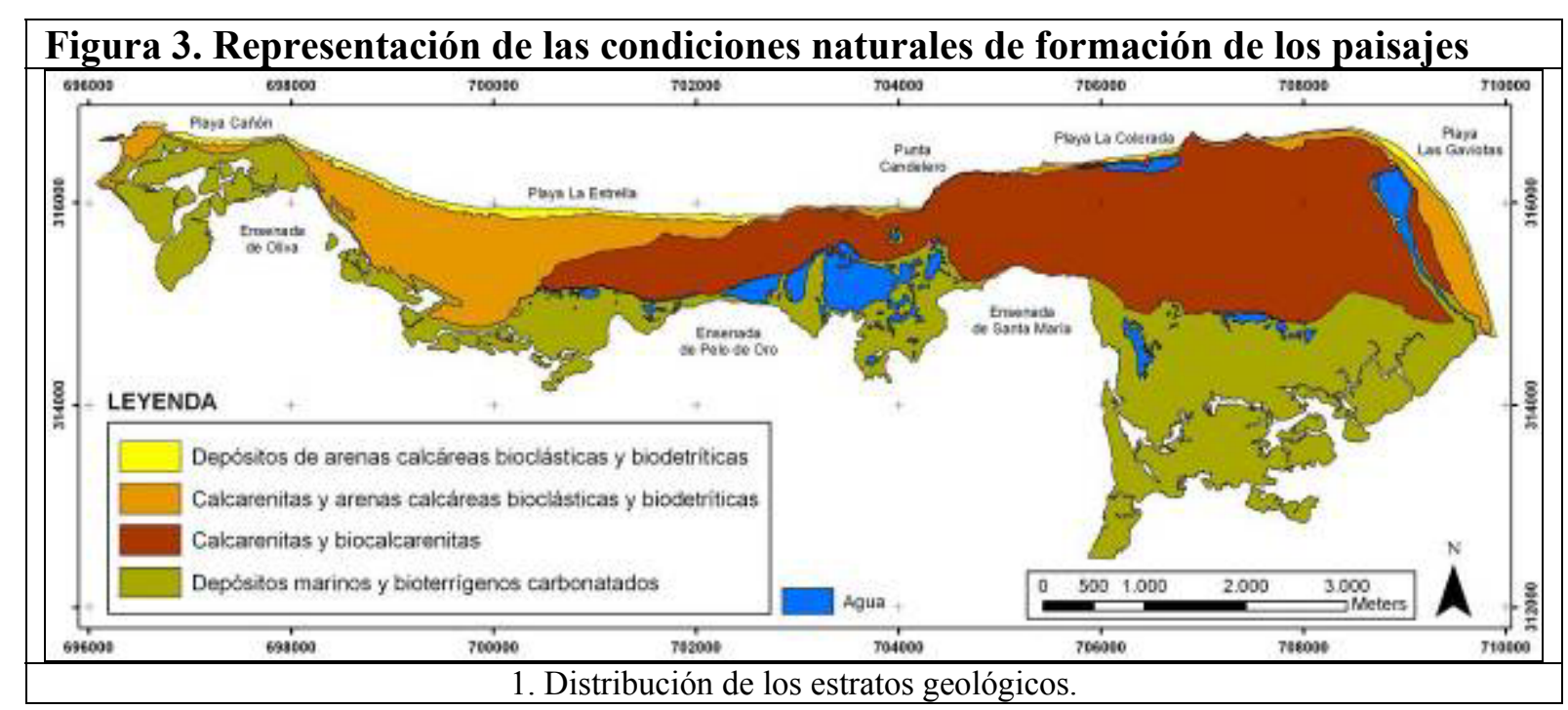




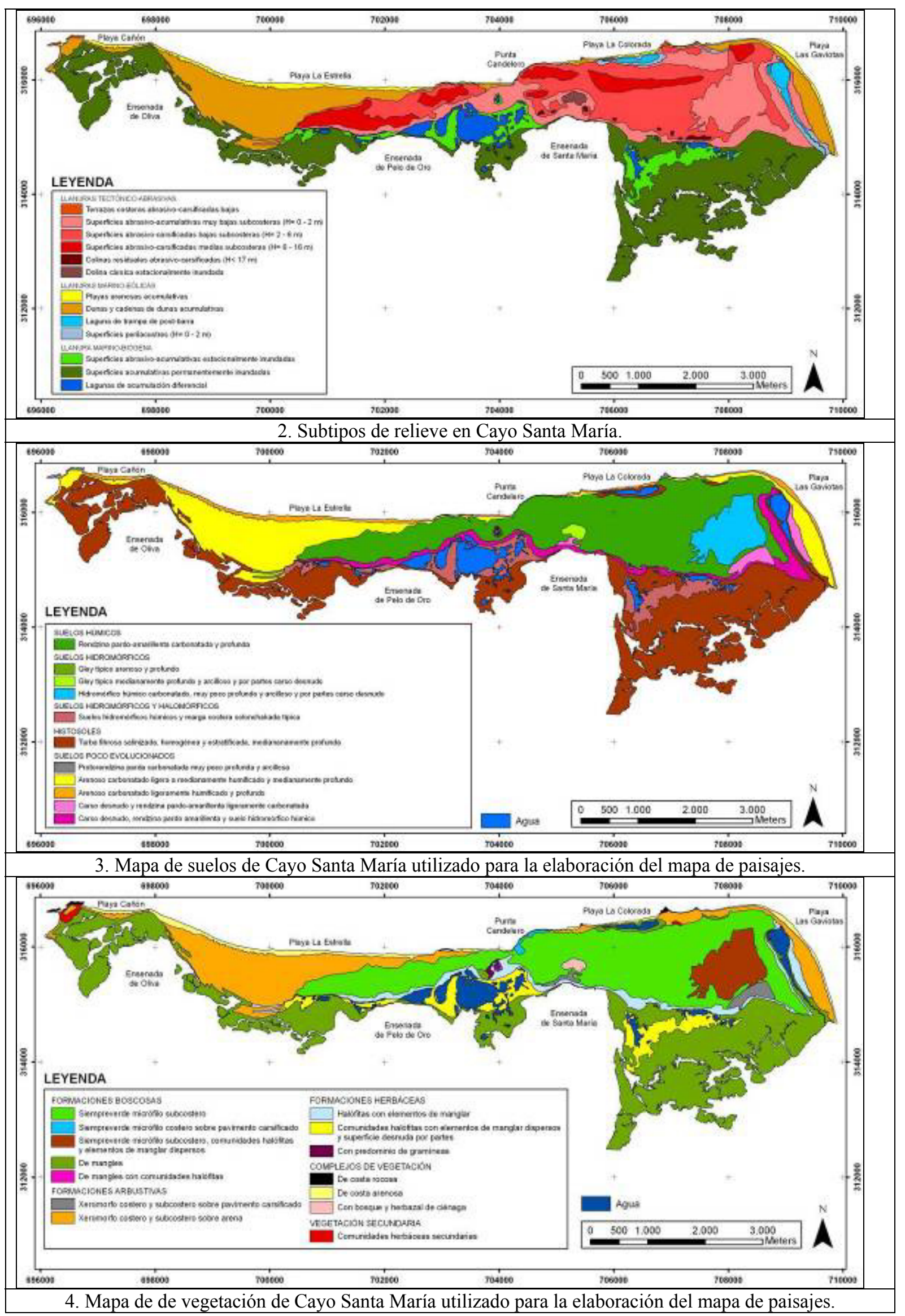

Fuente: Trujillo (1998), Noa et al. (2001), Pichardo (2003), Priego \& Isunza (2010). Elaboración propia. 


\section{Paisajes naturales}

A partir de la capa digital de curvas de nivel a escala 1:5.000 y de los mapas de estratigrafía, tipos de relieve, suelos y vegetación mostrados anteriormente, se elaboró el mapa de paisajes naturales a escala 1:10.000. Esta información se completó con trabajo de campo y análisis de imágenes de satélite. El mapa y la leyenda ampliada se encuentran en el Anexo 1. Para todos los análisis se utilizaron las unidades inferiores de paisaje (subcomarcas), identificadas en la leyenda ampliada sólo con números naturales.

\section{Condiciones socio-económicas}

Se estudiaron las condiciones socio-económicas del cayo: Estatus Legal y Planes de Manejo, Marco Institucional, Áreas Protegidas, Accesibilidad, Aspectos Históricos, Patrimonio Arqueológico, Aspectos Sociales, Economía e Infraestructuras.

No obstante, el análisis se centró en el epígrafe de Infraestructuras, puesto que los impactos ambientales dependen en gran medida del número y dimensiones de las mismas, así como su distribución en el cayo. A partir de la información obtenida del Plan de Ordenamiento Territorial de la Cayería (IPF, 2004) y de su Actualización (DPPFVC, 2010), se confeccionaron los mapas de ocupación del cayo, diferenciándose tres etapas (Figura 4):

1) Etapa "Sin Ocupación": Corresponde al estado original del cayo antes de cualquier intervención humana. Sobre esta etapa no se tienen registros, mapas ni referencias concretas. Sin embargo, para este estudio se considera que el estado original debía ser muy similar al del mapa de paisajes naturales elaborado.

2) Etapa "A" u "ocupación inicial": Se ha denominado así a la etapa anterior a la asimilación del cayo para el desarrollo del turismo. Las modificaciones llevadas a cabo por el ser humano se reducían a algunos caminos sin asfaltar, unas pocas trochas, un punto guardafronteras, un albergue militar y un muelle.

3) Etapa "B": Se corresponde con el estado actual de las construcciones. Se incluyen en esta etapa tanto las parcelas ya construidas y en funcionamiento, como las que se han comenzado a construir, y aquellas ya aprobadas en el plan de ordenamiento vigente.

4) Etapa "C": Es la fase de construcción que aún no se ha aprobado. Incluye parcelas y viales cuya construcción está pendiente de revisión en el plan.

\section{Aclaración sobre la valoración por etapas}

A pesar de haber definido un mayor número de etapas, conviene tener en cuenta que en este estudio se llevan a cabo dos valoraciones, según se explica a continuación:

a) Valoración de las unidades para su conservación en la Etapa A y de los impactos en la Etapa A (impactos que comienzan a producirse en esa etapa). De la síntesis de las dos resultan las afecciones a la sostenibilidad en la Etapa B o etapa actual.

b) Valoración de las unidades en la Etapa B o actual y de los impactos que comienzan a producirse en esta Etapa B. De la síntesis de las dos resulta una estimación de cuáles podrían ser las afecciones a la sostenibilidad de las unidades de paisaje en la Etapa C. 
Es decir, hay que tener en cuenta que los impactos que comenzaron a producirse con las construcciones en la Etapa A llevaron al cayo a un cambio de estado, que es el de la actual Etapa B. De ahí que haya que valorar de nuevo las unidades en esta Etapa B. Los impactos que comienzan en esta Etapa $\mathrm{B}$, presumiblemente llevarán al cayo a un cambio de estado (Etapa $\mathrm{C}$ ), con unas afecciones a la sostenibilidad distintas a las actuales.

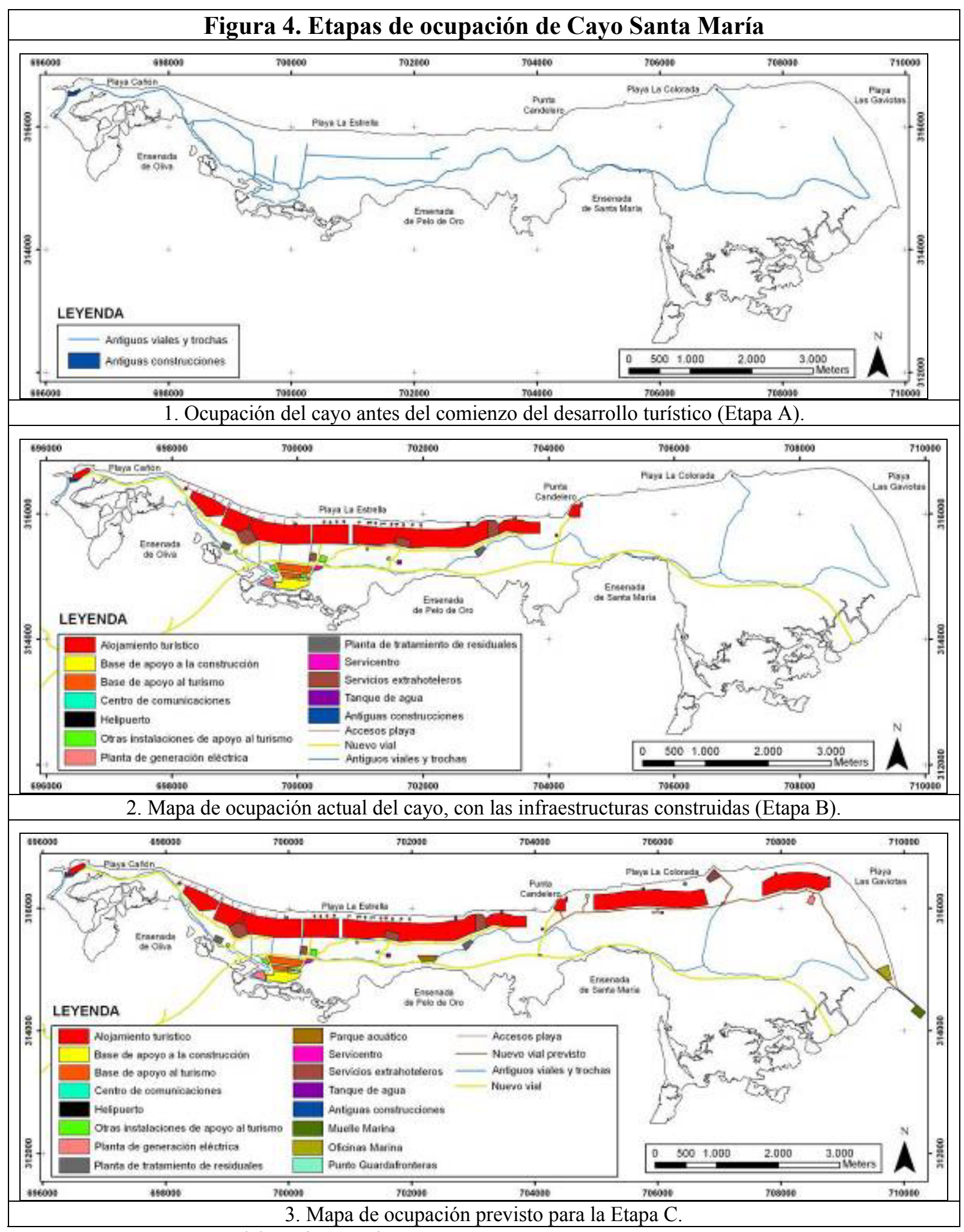

Fuente: DPPFVC, 2010. Elaboración propia. 


\section{DIAGNÓSTICO}

\section{Valoración de las unidades de paisaje para su conservación}

A continuación se muestran, de forma resumida, algunos ejemplos de las valoraciones realizadas para uno de los criterios.

\section{Probabilidad de inundación}

Para este análisis se utilizó el informe "Riesgos de penetraciones del mar en la cayería del nordeste de Villa Clara" (Trujillo \& Lamar, 2007). En dicho estudio, los autores calcularon las magnitudes máximas aproximadas de las inundaciones por penetraciones del mar asociadas a los ciclones tropicales. En el Cuadro 2 se muestra la sobreelevación según categorías de huracanes (Escala Saffir-Simpson. Sv: sobre-elevación por efecto del viento; So: sobre-elevación por efecto del oleaje; Sp: sobre-elevación por efecto de la presión atmosférica; S: sobre-elevación total.).

\section{Cuadro 2: Sobre-elevación del nivel del mar según categorías de huracanes (costa norte de Cayo Santa María).}

\begin{tabular}{||c|c|c|c|c||}
\hline Categoría & $\mathrm{S}_{\mathrm{V}}(\mathrm{m})$ & $\mathrm{S}_{\mathrm{O}}(\mathrm{m})$ & $\mathrm{S}_{\mathrm{P}}(\mathrm{m})$ & $\mathrm{S}(\mathrm{m})$ \\
\hline \hline SS1 & 0,52 & 0,13 & 0,35 & 1,00 \\
\hline SS2 & 0,90 & 0,17 & 0,43 & 1,50 \\
\hline SS3 & 1,15 & 0,49 & 0,61 & 2,25 \\
\hline SS4 & 2,03 & 0,64 & 0,83 & 3,50 \\
\hline SS5 & 3,18 & 0,87 & 0,95 & 5,00 \\
\hline
\end{tabular}

Fuente: Trujillo \& Lamar (2007).

A partir de esta información, y utilizando la capa de curvas de nivel a escala 1:5.000, se determinaron aquellas unidades del mapa de paisajes con mayor probabilidad de inundación. Hay que añadir que algunas de estas unidades no sólo se inundan por la penetración del mar, sino también debido al efecto de fuertes lluvias. Al igual que en el resto de valoraciones de este estudio, se utilizó una escala de 1 a 5. Así, las unidades que se inundan con la ocurrencia de huracanes de categoría 1, obtienen un valor 5. Las que se inundan con huracanes de categoría 2, tienen menor probabilidad de inundación (valor 4), y así sucesivamente.

Figura 5. Valoración de la probabilidad de inundación ante huracanes de categorías 1 a 5 (Las áreas más oscuras tienen mayor probabilidad).

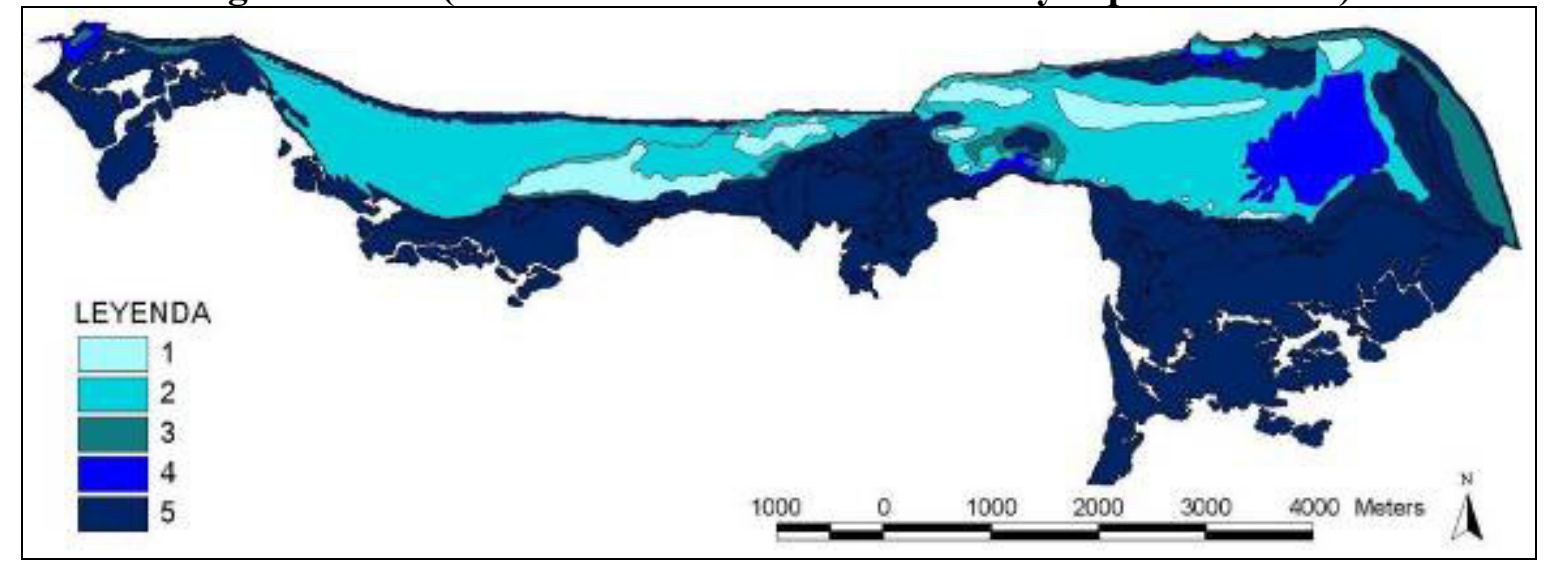

Fuente: Trujillo \& Lamar (2007). Elaboración propia. 
Como aspecto a tener en cuenta, cabe señalar que la probabilidad de inundación es un factor que no cambia entre una etapa y otra; por esto, se mantiene igual para las etapas A y B.

\section{Factibilidad constructiva en función del sustrato geológico}

En el "Estudio de la línea base ambiental de Cayo Santa María, escala 1:10.000" (Trujillo, 1998), se detallan los elementos ingeniero-geológicos del cayo y se analiza la capacidad de los mismos para acoger viales y construcciones, según los siguientes aspectos: factibilidad constructiva, riesgo geológico y susceptibilidad del medio. En el presente trabajo se trasladaron las valoraciones cualitativas de dicho informe a la habitual escala de 1 a 5 (Cuadro 3, Figura 6), considerando las anotaciones realizadas al respecto en el "Estudio Estratégico Ambiental del Plan de Desarrollo de Cayo Santa María" (Yeras, 2005). La factibilidad constructiva no cambia entre las Etapas A y B.

\section{Cuadro 3. Valoración de los factores de factibilidad constructiva.}

\begin{tabular}{|c|c|c|c|c|c|c|}
\hline \multicolumn{2}{|c|}{ UNIDADES } & \multicolumn{3}{|c|}{ FACTORES } & \multicolumn{2}{|l|}{ MEDIA } \\
\hline Localidades & Com. & $\begin{array}{c}\text { Riesgo } \\
\text { Geológico }\end{array}$ & $\begin{array}{l}\text { Factibilidad } \\
\text { constructiva }\end{array}$ & $\begin{array}{l}\text { Susceptibilidad } \\
\text { del medio }\end{array}$ & Media & Val. \\
\hline I.1-Terr. & 1 & 2 & 2 & 3 & 2,333333333 & 2 \\
\hline I.2-Play & 2 & 5 & 5 & 5 & 5 & 5 \\
\hline & 3 & 5 & 5 & 5 & 5 & 5 \\
\hline & 4 & 5 & 5 & 5 & 5 & 5 \\
\hline I.3-Dun. & 5 & 3 & 2 & 4 & 3 & 3 \\
\hline & 6 & 3 & 2 & 4 & 3 & 3 \\
\hline & 7 & 3 & 2 & 4 & 3 & 3 \\
\hline & 8 & 3 & 2 & 4 & 3 & 3 \\
\hline & 9 & 3 & 2 & 4 & 3 & 3 \\
\hline & 10 & 3 & 2 & 4 & 3 & 3 \\
\hline & 11 & 3 & 2 & 4 & 3 & 3 \\
\hline 1.4 Lag. Postb. & 12 & 4 & 4 & 5 & 4,333333333 & 4 \\
\hline 1.5-Sup.Perilac. & 13 & 4 & 4 & 5 & 4,333333333 & 4 \\
\hline II.1-SAA.0-2 & 14 & 2 & 2 & 3 & 2,333333333 & 2 \\
\hline & 15 & 2 & 2 & 3 & 2,333333333 & 2 \\
\hline & 16 & 3 & 2 & 3 & 2,666666667 & 3 \\
\hline & 17 & 2 & 3 & 4 & 3 & 3 \\
\hline & 18 & 2 & 2 & 3 & 2,333333333 & 2 \\
\hline & 19 & 2 & 2 & 3 & 2,333333333 & 2 \\
\hline & 20 & 2 & 2 & 3 & 2,333333333 & 2 \\
\hline & 21 & 2 & 2 & 3 & 2,333333333 & 2 \\
\hline & 22 & 2 & 2 & 3 & 2,333333333 & 2 \\
\hline II.2-SA.2-6 & 23 & 4 & 2 & 3 & 3 & 3 \\
\hline & 24 & 4 & 3 & 4 & 3,6666666667 & 4 \\
\hline & 25 & 4 & 3 & 4 & 3,6666666667 & 4 \\
\hline II.3-SA.6-16 & 26 & 4 & 4 & 3 & 3,666666667 & 4 \\
\hline & 27 & 4 & 4 & 3 & 3,666666667 & 4 \\
\hline II.4-Colinas & 28 & 4 & 4 & 3 & 3,666666667 & 4 \\
\hline II.5-Dolina & 29 & 4 & 5 & 5 & 4,666666667 & 5 \\
\hline III.1-SAA & 30 & 4 & 4 & 5 & 4,333333333 & 4 \\
\hline & 31 & 4 & 4 & 5 & 4,333333333 & 4 \\
\hline III.2-SAcum. & 32 & 4 & 4 & 5 & 4,333333333 & 4 \\
\hline III.3-Lagunas & 33 & 4 & 4 & 5 & 4,333333333 & 4 \\
\hline
\end{tabular}

Fuente: Trujillo (1998), Yeras (2005). Elaboración propia. 
Figura 6. Representación de la factibilidad constructiva (Etapas A y B).

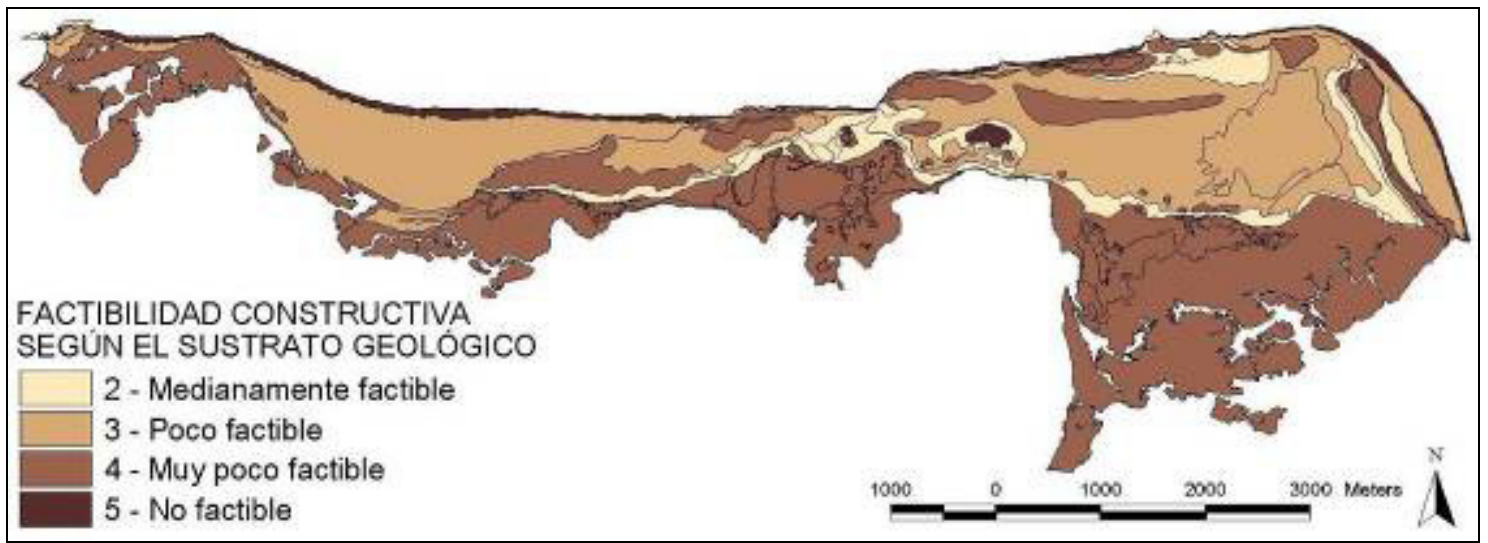

Fuente: Trujillo (1998), Yeras (2005). Elaboración propia.

\section{Síntesis de la valoración de las unidades de paisaje para su conservación}

Finalmente, se realizó una síntesis de la valoración de las unidades de paisaje para su conservación, para las Etapas A y B, resultando los siguientes valores (Cuadros 4 y 5), los cuales fueron representados de forma cartográfica (Figuras 15 y 16, en 'Discusión de los Resultados').

Cuadro 4. Síntesis de la valoración de las unidades de paisaje para su conservación (Etapa A).

\begin{tabular}{|c|c|c|c|c|c|c|c|c|c|c|}
\hline \multicolumn{2}{|c|}{ UNIDADES } & \multicolumn{7}{|c|}{ FACTORES } & \multicolumn{2}{|c|}{ VALORACIÓN } \\
\hline Localidades & Com. & $\begin{array}{c}\text { Estabilidad } \\
\text { de los } \\
\text { Paisajes }\end{array}$ & Biodiversidad & $\begin{array}{l}\text { Probabilidad } \\
\text { de inundación }\end{array}$ & $\begin{array}{l}\text { Areas de mayor } \\
\text { importancia } \\
\text { ecológica }\end{array}$ & $\begin{array}{c}\text { Potencial } \\
\text { Ecoturístico }\end{array}$ & $\begin{array}{c}\text { Grado de } \\
\text { conservación }\end{array}$ & $\begin{array}{l}\text { Factibilidad } \\
\text { constructiva }\end{array}$ & MEDIA & $\begin{array}{c}\text { REDONDEO } \\
\text { MEDIA }\end{array}$ \\
\hline I.1-Terr. & & 3 & 3 & 4 & 2 & 0 & 4 & 2 & 2,571428571 & 3 \\
\hline I.2-Play & & 4 & 3 & 5 & 5 & 1 & 5 & 5 & 4 & 4 \\
\hline & 3 & 4 & 3 & 5 & 3 & 4 & 5 & 5 & 4,142857143 & 4 \\
\hline & 4 & 4 & 3 & 5 & 2 & 0 & 5 & 5 & 3,428571429 & 3 \\
\hline I.3-Dun. & 5 & 2 & 3 & 2 & 5 & 4 & 4 & 3 & 3,285714286 & 3 \\
\hline & 6 & 3 & 3 & 3 & 2 & 4 & 5 & 3 & 3,285714286 & 3 \\
\hline & 7 & 2 & 4 & 2 & 5 & 0 & 5 & 3 & 3 & 3 \\
\hline & 8 & 2 & 2 & 5 & 1 & 0 & 4 & 3 & 2,428571429 & 2 \\
\hline & 9 & 3 & 3 & 2 & 3 & 0 & 5 & 3 & 2,714285714 & 3 \\
\hline & 10 & 3 & 3 & 4 & 1 & 0 & 2 & 3 & 2,285714286 & 2 \\
\hline & 11 & 3 & 1 & 5 & 2 & 0 & 4 & 3 & 2,571428571 & 3 \\
\hline 1.4 Lag. Postb. & 12 & 4 & 3 & 5 & 4 & 1 & 5 & 4 & 3,714285714 & 4 \\
\hline 1.5-Sup.Perilac. & 13 & 3 & 3 & 5 & 3 & 0 & 5 & 4 & 3,285714286 & 3 \\
\hline II.1-SAA.0-2 & 14 & 2 & 3 & 5 & 5 & 5 & 5 & 2 & 3,857142857 & 4 \\
\hline & 15 & 2 & 4 & 2 & 3 & 0 & 5 & 2 & 2,571428571 & 3 \\
\hline & 16 & 2 & 4 & 4 & 5 & 5 & 5 & 2 & 3,857142857 & 4 \\
\hline & 17 & 2 & 4 & 5 & 3 & 5 & 5 & 3 & 3,857142857 & 4 \\
\hline & 18 & 2 & 3 & 4 & 3 & 2 & 5 & 2 & 3 & 3 \\
\hline & 19 & 2 & 3 & 5 & 3 & 0 & 5 & 2 & 2,857142857 & 3 \\
\hline & 20 & 3 & 4 & 5 & 5 & 5 & 5 & 2 & 4,142857143 & 4 \\
\hline & 21 & 1 & 3 & 5 & 3 & 0 & 5 & 2 & 2,714285714 & 3 \\
\hline & 22 & 2 & 4 & 5 & 3 & 1 & 3 & 2 & 2,857142857 & 3 \\
\hline II.2-SA.2-6 & 23 & 2 & 4 & 2 & 5 & 5 & 5 & 4 & 3,857142857 & 4 \\
\hline & 24 & 2 & 4 & 2 & 3 & 0 & 5 & 4 & 2,857142857 & 3 \\
\hline & 25 & 2 & 3 & 2 & 3 & 1 & 4 & 4 & 2,714285714 & 3 \\
\hline II.3-SA.6-16 & 26 & 2 & 4 & 1 & 5 & 5 & 5 & 4 & 3,714285714 & 4 \\
\hline & 27 & 2 & 3 & 1 & 3 & 3 & 5 & 4 & 3 & 3 \\
\hline II.4-Colinas & 28 & 2 & 4 & 1 & 5 & 2 & 5 & 4 & 3,285714286 & 3 \\
\hline II.5-Dolina & 29 & 3 & 4 & 5 & 5 & 5 & 5 & 5 & 4,571428571 & 5 \\
\hline III.1-SAA & 30 & 3 & 4 & 5 & 3 & 0 & 5 & 4 & 3,428571429 & 3 \\
\hline & 31 & 3 & 2 & 5 & 3 & 1 & 5 & 4 & 3,285714286 & 3 \\
\hline III.2-SAcum. & 32 & 3 & 2 & 5 & 3 & 1 & 5 & 4 & 3,285714286 & 3 \\
\hline III.3-Lagunas & 33 & 4 & 2 & 5 & 5 & 2 & 5 & 4 & 3,857142857 & 4 \\
\hline
\end{tabular}

Fuente: Elaboración propia. 


\section{Cuadro 5. Síntesis de la valoración de las unidades de paisaje para su conservación}

(Etapa B).

\begin{tabular}{|c|c|c|c|c|c|c|c|c|c|c|}
\hline \multicolumn{2}{|c|}{ UNIDADES } & \multicolumn{7}{|c|}{ VALORES } & \multicolumn{2}{|c|}{ VALORACIÓN } \\
\hline Localidades & Com. & $\begin{array}{l}\text { Estabilidad } \\
\text { de los } \\
\text { Paisajes }\end{array}$ & Biodiversidad & $\begin{array}{c}\text { Probabilidad } \\
\text { de } \\
\text { inundación }\end{array}$ & $\begin{array}{l}\text { Areas de mayor } \\
\text { importancia } \\
\text { ecológica }\end{array}$ & $\begin{array}{c}\text { Potencial } \\
\text { Ecoturistico }\end{array}$ & $\begin{array}{c}\text { Grado de } \\
\text { conservación }\end{array}$ & $\begin{array}{l}\text { Factibilidad } \\
\text { constructiva }\end{array}$ & MEDIA & $\begin{array}{c}\text { REDONDEO } \\
\text { MEDIA }\end{array}$ \\
\hline I.1-Terr. & & 3 & 3 & 4 & 2 & 0 & 4 & 2 & 2,571428571 & 3 \\
\hline 1.2-Play & 2 & 4 & 2 & 5 & 4 & 1 & 3 & 5 & 3,428571429 & 3 \\
\hline & 3 & 4 & 3 & 5 & 3 & 4 & 5 & 5 & 4,142857143 & 4 \\
\hline & 4 & 4 & 3 & 5 & 2 & 0 & 5 & 5 & 3,428571429 & 3 \\
\hline 1.3-Dun. & 5 & 3 & 1 & 2 & 1 & 0 & 1 & 3 & 1,571428571 & 2 \\
\hline & 6 & 2 & 3 & 3 & 2 & 4 & 5 & 3 & 3,142857143 & 3 \\
\hline & 7 & 2 & 3 & 2 & 3 & 0 & 4 & 3 & 2,428571429 & 2 \\
\hline & 8 & 3 & 2 & 5 & 1 & 0 & 1 & 3 & 2,142857143 & 2 \\
\hline & 9 & 3 & 2 & 2 & 2 & 0 & 3 & 3 & 2,142857143 & 2 \\
\hline & 10 & 3 & 1 & 4 & 1 & 0 & 2 & 3 & 2 & 2 \\
\hline & 11 & 3 & 1 & 5 & 1 & 0 & 1 & 3 & 2 & 2 \\
\hline 1.4 Lag. Postb. & 12 & 4 & 3 & 5 & 4 & 1 & 5 & 4 & 3,714285714 & 4 \\
\hline 1.5-Sup.Perilac. & 13 & 3 & 3 & 5 & 3 & 0 & 5 & 4 & 3,285714286 & 3 \\
\hline II.1-SAA.0-2 & 14 & 2 & 3 & 5 & 4 & 5 & 3 & 2 & 3,428571429 & 3 \\
\hline & 15 & 2 & 3 & 2 & 3 & 0 & 3 & 2 & 2,142857143 & 2 \\
\hline & 16 & 2 & 4 & 4 & 5 & 5 & 5 & 3 & 4 & 4 \\
\hline & 17 & 2 & 4 & 5 & 3 & 5 & 4 & 3 & 3,714285714 & 4 \\
\hline & 18 & 2 & 3 & 4 & 3 & 2 & 4 & 2 & 2,857142857 & 3 \\
\hline & 19 & 2 & 3 & 5 & 3 & 0 & 4 & 2 & 2,714285714 & 3 \\
\hline & 20 & 3 & 4 & 5 & 5 & 4 & 3 & 2 & 3,714285714 & 4 \\
\hline & 21 & 1 & 3 & 5 & 3 & 0 & 5 & 2 & 2,714285714 & 3 \\
\hline & 22 & 2 & 4 & 5 & 3 & 1 & 3 & 2 & 2,857142857 & 3 \\
\hline II.2-SA.2-6 & 23 & 2 & 3 & 2 & $\overline{4}$ & 5 & 3 & 3 & 3,142857143 & 3 \\
\hline & 24 & 3 & 3 & 2 & 3 & 0 & 3 & 4 & 2,571428571 & 3 \\
\hline & 25 & 3 & 3 & 2 & 2 & 1 & 3 & 4 & 2,571428571 & 3 \\
\hline II.3-SA.6-16 & 26 & 2 & 3 & 1 & 4 & 3 & 3 & 4 & 2,831291429 & 3 \\
\hline & 27 & 3 & 3 & 1 & 1 & 0 & 1 & 4 & 1,857142857 & 2 \\
\hline II.4-Colinas & 28 & 2 & 4 & 1 & 5 & 2 & 5 & 4 & 3,285714286 & 3 \\
\hline III.5-Dolina & 29 & 3 & 4 & 5 & 5 & 5 & 5 & 5 & 4,571428571 & 5 \\
\hline IIII.1-SAA & 30 & 3 & 4 & 5 & 3 & 0 & 5 & 4 & 3,428571429 & 3 \\
\hline & 31 & 3 & 2 & 5 & 3 & 1 & 4 & 4 & 3,142857143 & 3 \\
\hline III.2-SAcum. & 32 & 3 & 2 & 5 & 3 & 1 & 4 & 4 & 3,142857143 & 3 \\
\hline III.3-Lagunas & 33 & 4 & 2 & 5 & 5 & 1 & 4 & 4 & 3,571428571 & 4 \\
\hline
\end{tabular}

Fuente: Elaboración propia.

\section{Valoración de los impactos ambientales}

A continuación se muestran, de forma resumida, algunos ejemplos de los análisis y valoraciones llevados a cabo para los impactos ambientales.

\section{Análisis de fragmentación}

El mapa de paisajes elaborado a escala 1:10.000, con el que se trabaja para todos los análisis, consta de 145 polígonos de unidades de paisajes sin tener en cuenta ninguna transformación. Superponiendo a éste la capa de antiguas infraestructuras y caminos, se obtienen 210 polígonos (aumento en la fragmentación del $44,83 \%$ con respecto a la Etapa 'Sin ocupación'). Posteriormente, a este mapa se le superpusieron las capas correspondientes a las nuevas construcciones realizadas y las previstas según las Etapas B y C. Los incrementos en la fragmentación se muestran en el Cuadro 6.

Cuadro 6. Fragmentación en las diferentes etapas de ocupación del cayo.

\begin{tabular}{|l|c|c|c|c|}
\hline $\begin{array}{l}\text { ETAPA DE } \\
\text { OCUPACIÓN }\end{array}$ & $\begin{array}{c}\mathrm{N}^{\mathrm{o}} \text { de } \\
\text { Polígonos }\end{array}$ & $\begin{array}{c}\text { Incremento } \\
\text { parcial }\end{array}$ & $\begin{array}{c}\text { Incremento } \\
\text { Acumulado }\end{array}$ & $\begin{array}{c}\text { Fragmentación } \\
\text { Acumulada }\end{array}$ \\
\hline Sin ocupación & 145 & - & - & $0,00 \%$ \\
\hline Etapa A & 210 & 65 & 65 & $44,83 \%$ \\
\hline Etapa B & 766 & 556 & 621 & $428,28 \%$ \\
\hline Etapa C & 854 & 88 & 709 & $488,97 \%$ \\
\hline
\end{tabular}

Fuente: Elaboración propia. 
Seguidamente, se analizó el incremento del número de polígonos en cada unidad de paisaje a nivel de subcomarcas (Figura 7) y se asignó un valor de fragmentación en función de los siguientes rangos de incremento (Figura 8):

- Valor 0: Sin incremento

- Valor 1: De 1 a 10 polígonos

- Valor 2: De 11 a 20

- Valor 3: De 21 a 30

- Valor 4: De 31 a 40

- Valor 5: Más de 40 polígonos

Figura 7. Aumento en el número de polígonos de las unidades de paisaje desde el comienzo de la asimilación turística (Etapa A) hasta la actualidad (Etapa B).

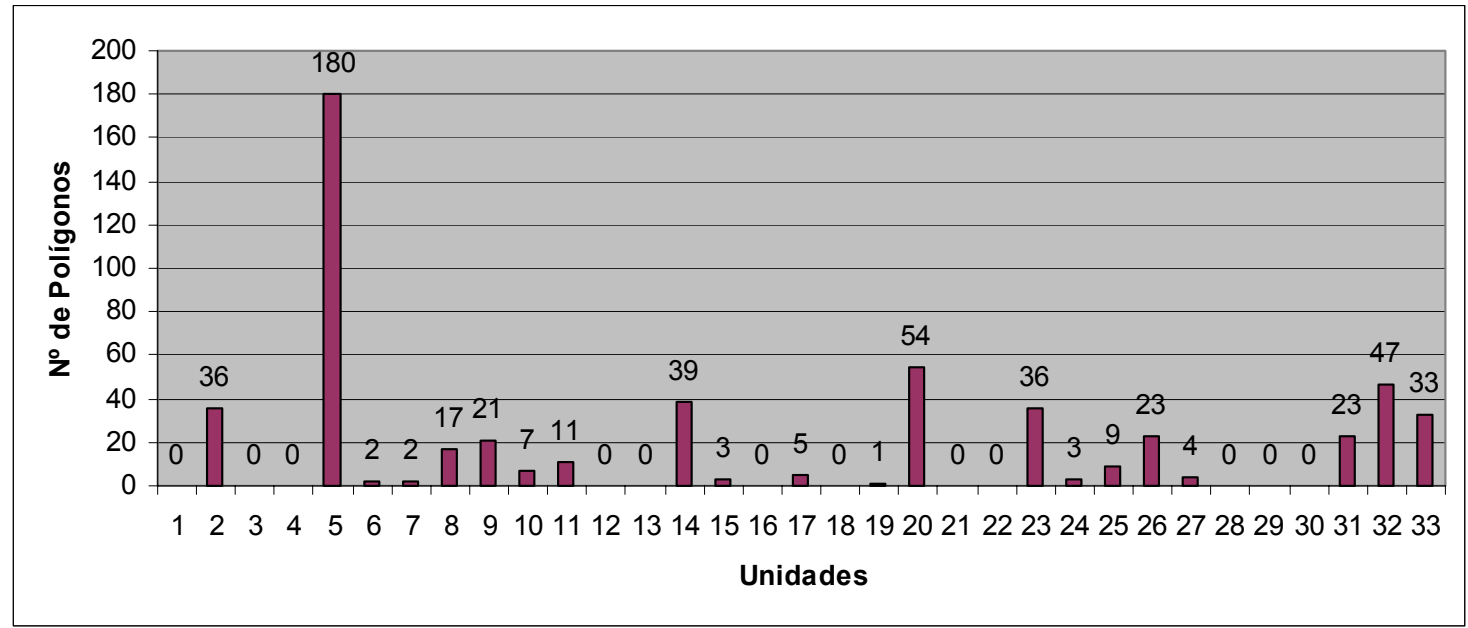

Fuente: Elaboración propia.

Figura 8. Fragmentación del cayo acumulada hasta la etapa actual (Etapa B).

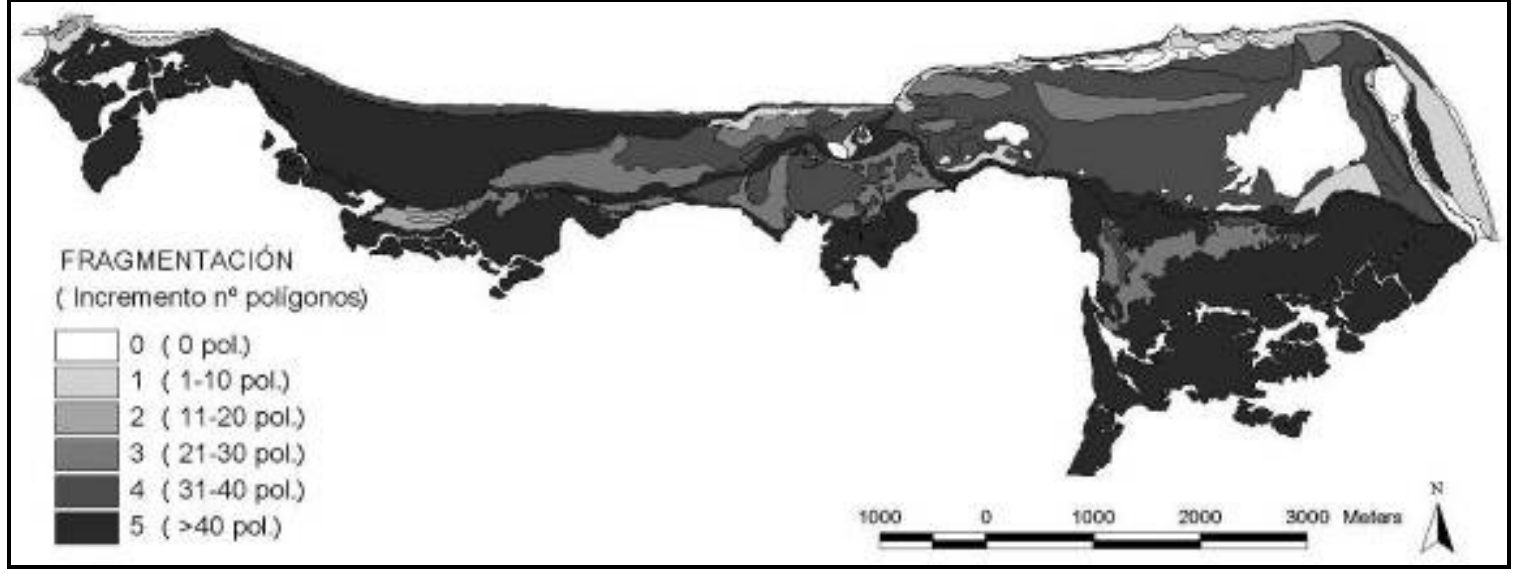

Fuente: Elaboración propia.

Análisis de la pérdida de hábitat natural

Antes del comienzo de la asimilación turística, las antiguas infraestructuras sumaban un área total de 8,975 ha $\left(0,08975 \mathrm{~km}^{2}\right)$. El área total del cayo con la que se está trabajando es de 2136,505 ha $\left(21,36505 \mathrm{~km}^{2}\right)$, por lo que la superficie ocupada por aquellas infraestructuras suponía tan sólo el 0,42\%. 
Las nuevas construcciones y viales hasta la fecha suman 216,576 ha $\left(2,1657 \mathrm{~km}^{2}\right)$, lo que supone un $10,14 \%$ del área total del cayo y el $18,19 \%$ de la superficie emergida. A pesar de que este porcentaje podría parecer bajo, se procedió a analizar la incidencia de la destrucción del hábitat por unidad de paisaje de forma similar al caso de la fragmentación. La Figura 9 representa el porcentaje de área de cada unidad de paisaje que ha desaparecido a causa de la instalación y construcción de las infraestructuras asociadas a la asimilación turística.

Figura 9. Porcentaje de hábitat desaparecido en la actualidad (Etapa B) desde el comienzo de las construcciones en la Etapa $\mathbf{A}$.

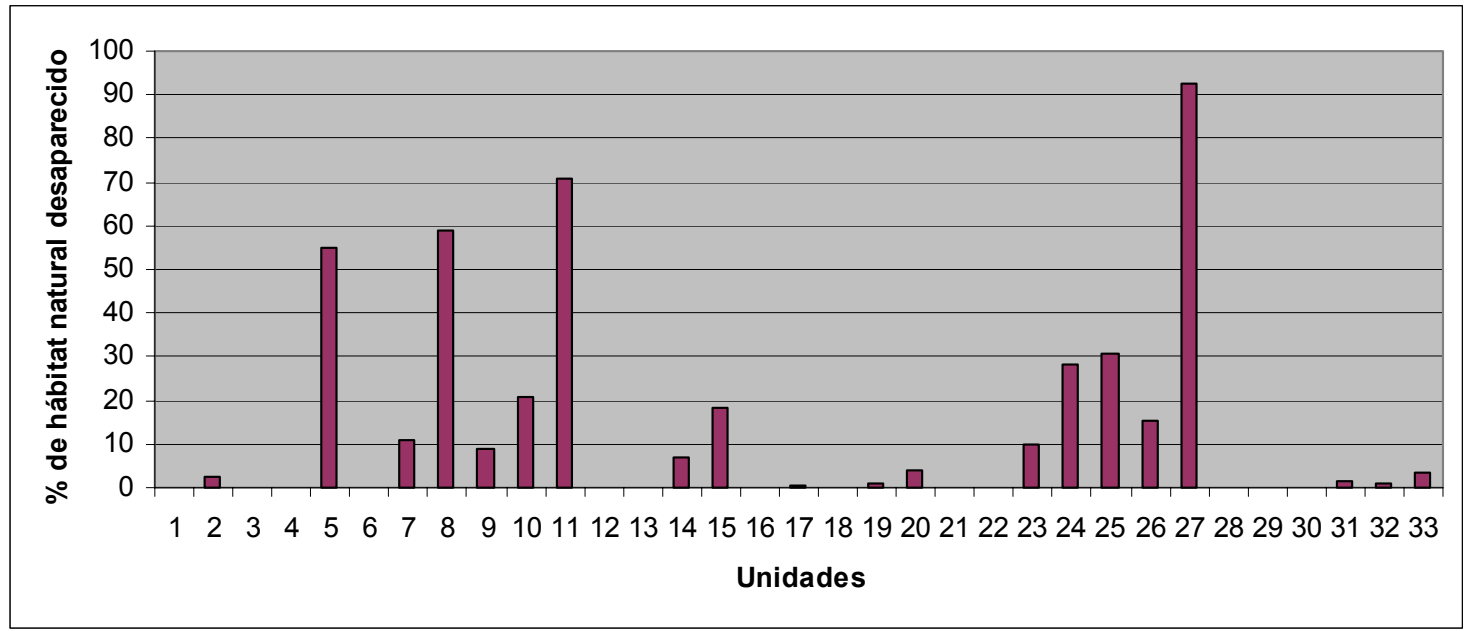

Fuente: Elaboración propia.

A continuación se establecieron intervalos de valoración para dichos porcentajes, los cuales se asignaron a cada unidad de paisaje, como sigue (Figura 10):

- Valor 0: Sin pérdida de hábitat

- Valor 1: De 0\% a 10\%

- Valor 2: De 10\% a 20\%

- Valor 3: De 20\% a 30\%

- Valor 4: De 30\% a 40\%

- Valor 5: Más de 40\%

Figura 10. Representación de la valoración de pérdida de hábitat natural en cada unidad entre las Etapas A y B.

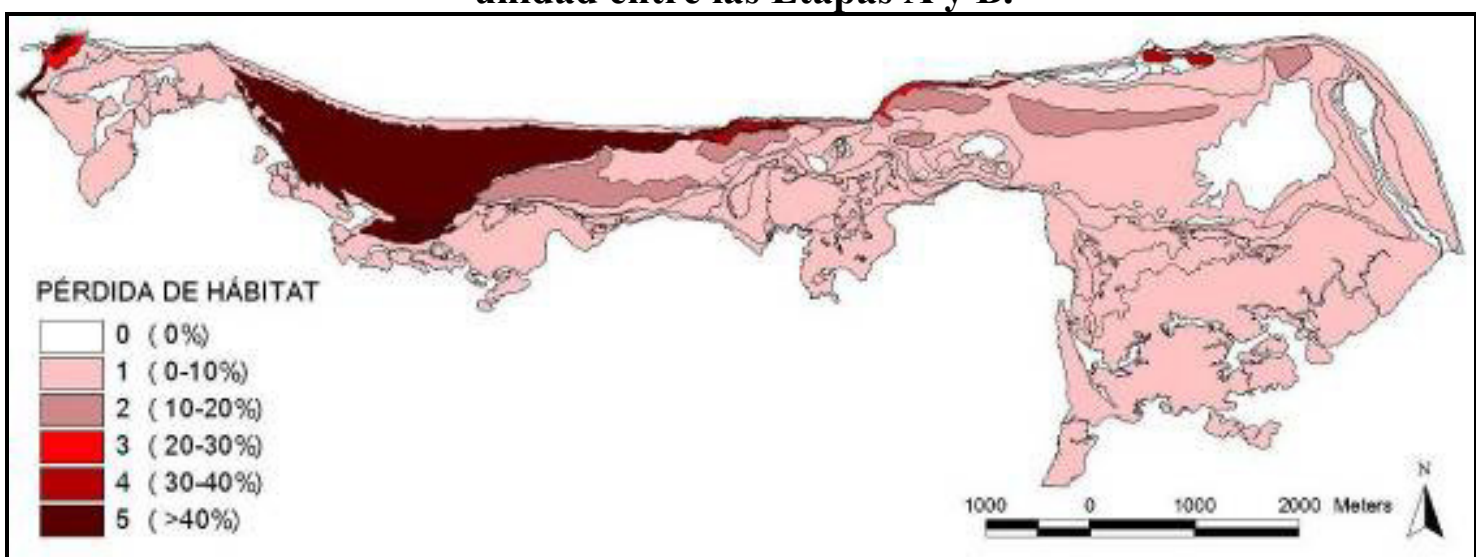

Fuente: Elaboración propia. 


\section{Síntesis de la valoración de los impactos ambientales}

A continuación, se llevó a cabo una síntesis de las valoraciones de todos los impactos para ambas etapas (Cuadros 7 y 8; Figuras 17 y 18, en 'Discusión de los Resultados').

Cuadro 7. Síntesis de la valoración de los impactos ambientales (Etapa A).

\begin{tabular}{|c|c|c|c|c|c|c|c|c|c|}
\hline \multicolumn{2}{|c|}{ UNIDADES } & \multicolumn{6}{|c|}{ IMPACTOS } & \multirow[b]{2}{*}{ MEDIA } & \multirow[b]{2}{*}{$\begin{array}{c}\text { REDONDEO } \\
\text { MEDIA }\end{array}$} \\
\hline Localidades & Com. & $\begin{array}{c}\text { Pérdida de } \\
\text { Hábitat } \\
\text { Natural }\end{array}$ & Fragmentación & $\begin{array}{l}\text { Pérdida } \\
\text { calidad } \\
\text { estética }\end{array}$ & \begin{tabular}{|c|} 
Afecciones a \\
la Biodoversid
\end{tabular} & $\begin{array}{l}\text { Alterac. áreas } \\
\text { imp. Ecológica }\end{array}$ & Contaminación & & \\
\hline I.1-Terr. & 1 & 0 & 0 & 1 & 0 & 0 & 1 & 0,333333333 & 0 \\
\hline \multirow[t]{3}{*}{ 1.2-Play } & 2 & 1 & 4 & 2 & 3 & 3 & 2 & 2,5 & 3 \\
\hline & 3 & 0 & 0 & 2 & 0 & 0 & 0 & 0,333333333 & 0 \\
\hline & 4 & 0 & 0 & 1 & 0 & 0 & 0 & 0,166666667 & 0 \\
\hline \multirow[t]{7}{*}{ 1.3-Dun. } & 5 & 5 & 5 & 5 & 4 & 5 & 4 & 4,666666667 & 5 \\
\hline & 6 & 1 & 1 & 0 & 2 & 1 & 1 & 1 & 1 \\
\hline & $\overline{7}$ & 2 & 1 & 2 & 2 & 3 & 2 & 2 & 2 \\
\hline & 8 & 5 & 2 & 3 & 4 & 3 & 4 & 3,5 & 4 \\
\hline & 9 & 1 & 3 & 3 & 2 & 2 & 2 & 2,166666667 & 2 \\
\hline & 10 & 3 & 1 & 4 & 2 & 2 & 3 & 2,5 & 3 \\
\hline & 11 & 5 & 2 & 5 & 4 & 3 & 4 & 3,833333333 & 4 \\
\hline 1.4 Lag. Postb. & 12 & 0 & 0 & 1 & 0 & 0 & 0 & 0,166666667 & 0 \\
\hline I.5-Sup.Perilac. & 13 & 0 & 0 & 0 & 0 & 0 & 0 & 0,066666667 & 0 \\
\hline \multirow[t]{9}{*}{ II.1-SAA.0-2 } & 14 & 1 & 4 & 3 & 3 & 3 & 3 & 2,833333333 & 3 \\
\hline & 15 & 2 & 1 & 4 & 2 & 2 & 2 & 2,166666667 & 2 \\
\hline & 16 & 0 & 0 & 0 & 0 & 0 & 0 & 0 & 0 \\
\hline & $\overline{17}$ & 1 & 1 & 1 & 2 & 2 & 1 & 1,333333333 & 1 \\
\hline & 18 & 0 & 0 & 0 & 0 & 0 & 1 & 0,166666667 & 0 \\
\hline & 19 & 1 & 1 & 1 & 2 & 2 & 1 & 1,333333333 & 1 \\
\hline & 20 & 1 & 5 & 4 & 3 & 4 & 3 & 3,333333333 & 3 \\
\hline & 21 & 0 & 0 & 0 & 0 & 0 & 1 & 0,166666667 & 0 \\
\hline & 22 & 0 & 0 & 0 & 0 & 0 & 1 & 0,166666667 & 0 \\
\hline \multirow[t]{3}{*}{ 11.2-SA.2-6 } & 23 & 1 & 4 & 4 & 3 & 3 & 2 & 2,833333333 & 3 \\
\hline & 24 & 3 & 1 & 4 & 3 & 2 & 2 & 2,5 & 3 \\
\hline & 25 & 4 & 1 & 4 & 3 & 3 & 2 & 2,833333333 & 3 \\
\hline \multirow[t]{2}{*}{ II.3-SA.6-16 } & $\overline{26}$ & 2 & 3 & 4 & 3 & 3 & 2 & 2,833333333 & 3 \\
\hline & 27 & 5 & 1 & 5 & 4 & 3 & 3 & 3,5 & 4 \\
\hline II.4-Colinas & 28 & 0 & 0 & 0 & 0 & 0 & 0 & 0 & 0 \\
\hline II.5-Dolina & 29 & 0 & 0 & 0 & 0 & 0 & 0 & 0 & 0 \\
\hline \multirow[t]{2}{*}{ III.1-SAA } & 30 & 0 & 0 & 0 & 0 & 0 & 0 & 0 & 0 \\
\hline & 31 & 1 & 3 & 2 & 2 & 2 & 2 & 2 & 2 \\
\hline III.2-SAcum. & 32 & 1 & 5 & 2 & 3 & 3 & 2 & 2,666666667 & 3 \\
\hline III.3-Lagunas & 33 & 1 & 4 & 2 & 2 & 3 & 2 & 2,333333333 & 2 \\
\hline
\end{tabular}

Fuente: Elaboración propia. 
Cuadro 8. Síntesis de la valoración de los impactos ambientales (Etapa B).

\begin{tabular}{|c|c|c|c|c|c|c|c|c|c|}
\hline \multicolumn{2}{|c|}{ UNIDADES } & \multicolumn{6}{|c|}{ IMPACTOS } & \multicolumn{2}{|c|}{ VALORACIÓN } \\
\hline Localidades & Com. & $\begin{array}{c}\text { Pérdida de } \\
\text { Hábitat Natural }\end{array}$ & Fragmentación & $\begin{array}{c}\text { Pérdida calidad } \\
\text { estética }\end{array}$ & $\begin{array}{c}\text { Afecciones a la } \\
\text { Biodoversid }\end{array}$ & $\begin{array}{l}\text { Alterac. áreas } \\
\text { imp. Ecológica }\end{array}$ & Contaminación & MEDIA & $\begin{array}{c}\text { REDONDEO } \\
\text { MEDIA }\end{array}$ \\
\hline I.1-Terr. & 1 & 1 & 1 & 2 & 2 & 1 & 2 & 1,5000 & 2 \\
\hline \multirow{3}{*}{ I.2-Play } & 2 & 1 & 4 & 2 & 3 & 3 & 2 & 2,5000 & 3 \\
\hline & 3 & 0 & 0 & 2 & 0 & 0 & 2 & 0,6667 & 1 \\
\hline & 4 & 1 & 1 & 1 & 2 & 1 & 3 & 1,5000 & 2 \\
\hline \multirow{7}{*}{ 1.3-Dun. } & 5 & 5 & 5 & 5 & 4 & 5 & 4 & 4,6667 & 5 \\
\hline & 6 & 1 & 1 & 3 & 2 & 1 & 3 & 1,8333 & 2 \\
\hline & 7 & 2 & 1 & 2 & 2 & 3 & 2 & 2,0000 & 2 \\
\hline & 8 & 5 & 2 & 3 & 4 & 3 & 4 & 3,5000 & 4 \\
\hline & 9 & 1 & 3 & 3 & 2 & 2 & 2 & 2,1667 & 2 \\
\hline & 10 & 3 & 1 & 4 & 2 & 2 & 3 & 2,5000 & 3 \\
\hline & 11 & 5 & 2 & 5 & 4 & 3 & 4 & 3,8333 & 4 \\
\hline 1.4 Lag. Postb. & 12 & 1 & 1 & 1 & 2 & 2 & 3 & 1,6667 & 2 \\
\hline 1.5-Sup.Perilac. & 13 & 2 & 2 & 3 & 2 & 2 & 3 & 2,3333 & 2 \\
\hline \multirow[t]{9}{*}{ II.1-SAA.0-2 } & 14 & 2 & 5 & 4 & 3 & 4 & 4 & 3,6667 & 4 \\
\hline & 15 & 3 & 1 & 4 & 2 & 2 & 2 & 2,3333 & 2 \\
\hline & 16 & 1 & 1 & 1 & 2 & 2 & 2 & 1,5000 & 2 \\
\hline & 17 & 1 & 1 & 1 & 2 & 2 & 1 & 1,3333 & 1 \\
\hline & 18 & 1 & 1 & 3 & 2 & 2 & 2 & 1,8333 & 2 \\
\hline & 19 & 1 & 1 & 1 & 2 & 2 & 1 & 1,3333 & 1 \\
\hline & 20 & 1 & 5 & 4 & 3 & 4 & 4 & 3,5000 & 4 \\
\hline & 21 & 0 & 0 & 0 & 0 & 0 & 1 & 0,1667 & 0 \\
\hline & 22 & 2 & 1 & 1 & 2 & 2 & 2 & 1,6667 & 2 \\
\hline \multirow[t]{3}{*}{ 11.2-SA.2-6 } & 23 & 3 & 5 & 5 & 4 & 4 & 4 & 4,1667 & 4 \\
\hline & 24 & 3 & 1 & 4 & 3 & 2 & 2 & 2,5000 & 3 \\
\hline & 25 & 5 & 2 & 5 & 3 & 3 & 4 & 3,6667 & 4 \\
\hline \multirow[t]{2}{*}{ II.3-SA.6-16 } & 26 & 4 & 4 & 5 & 4 & 4 & 4 & 4,1667 & 4 \\
\hline & 27 & 5 & 1 & 5 & 4 & 3 & 4 & 3,6667 & 4 \\
\hline II.4-Colinas & 28 & 0 & 0 & 0 & 0 & 0 & 0 & 0,0000 & 0 \\
\hline II.5-Dolina & 29 & 0 & 0 & 0 & 0 & 0 & 0 & 0,0000 & 0 \\
\hline \multirow{2}{*}{ III.1-SAA } & 30 & 0 & 0 & 0 & 0 & 0 & 0 & 0,0000 & 0 \\
\hline & 31 & 1 & 3 & 2 & 2 & 2 & 2 & 2,0000 & 2 \\
\hline III.2-SAcum. & 32 & 1 & 5 & 3 & 3 & 3 & 3 & 3,0000 & 3 \\
\hline III.3-Lagunas & 33 & 1 & 4 & 2 & 2 & 3 & 2 & 2,3333 & 2 \\
\hline
\end{tabular}

Fuente: Elaboración propia.

\section{DISCUSIÓN DE LOS RESULTADOS}

\section{Valoración de las unidades de paisaje para su conservación}

\section{Valoración de la estabilidad de los paisajes naturales}

Según el análisis realizado, tan sólo una pequeña unidad de la superficie emergida del cayo resulta como 'Muy Estable' (unidad 21), lo cual es lógico si se tiene en cuenta que este cayo es un territorio relativamente joven y todavía en formación. Como aspecto a tener en cuenta destaca la inestabilidad de las playas y las lagunas.

\section{Valoración de la biodiversidad en las unidades de paisajes naturales}

Como era de esperar, las unidades con vegetación de bosque siempreverde son las que por lo general obtienen un valor de biodiversidad 'Alto', con pocas excepciones. Las unidades con matorral xeromorfo presentan un valor 'Medio'.

\section{Valoración de la probabilidad de inundación}

Destaca la presencia de áreas hoteleras en zonas de probabilidad de inundación 'Muy Alta' (Figura 11) y 'Alta' (Figura 12); además de los viales que se han construido en zonas de máxima probabilidad de inundación (Figura 12). 


\section{Figura 11. Áreas hoteleras en zonas de máxima probabilidad de inundación.}

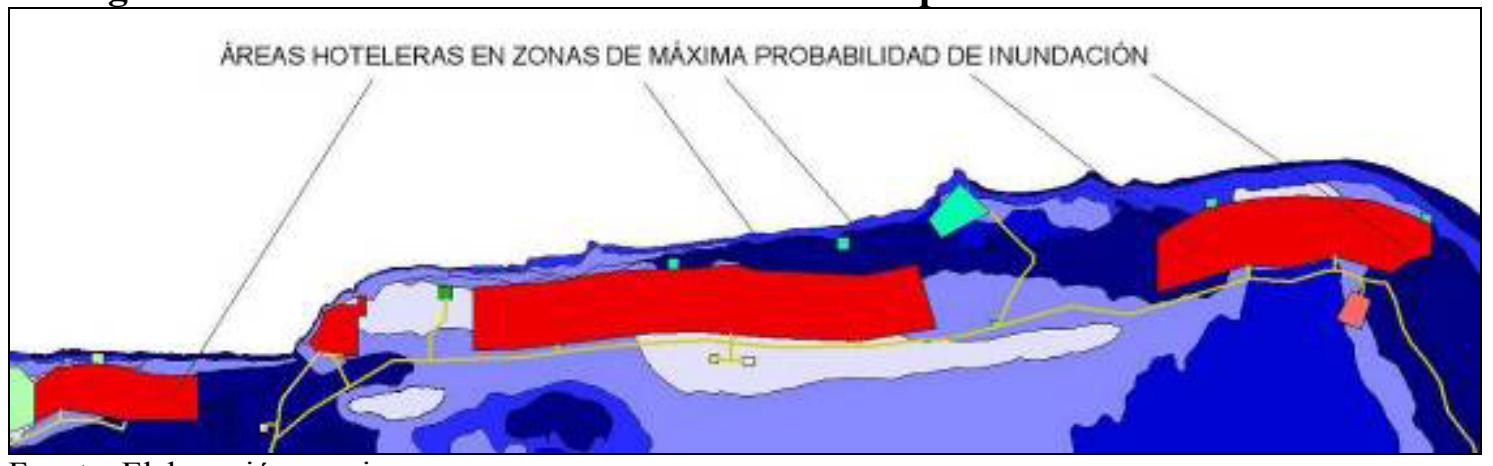

Fuente: Elaboración propia.

Figura 12. Áreas hoteleras en zonas de media y alta probabilidad de inundación.

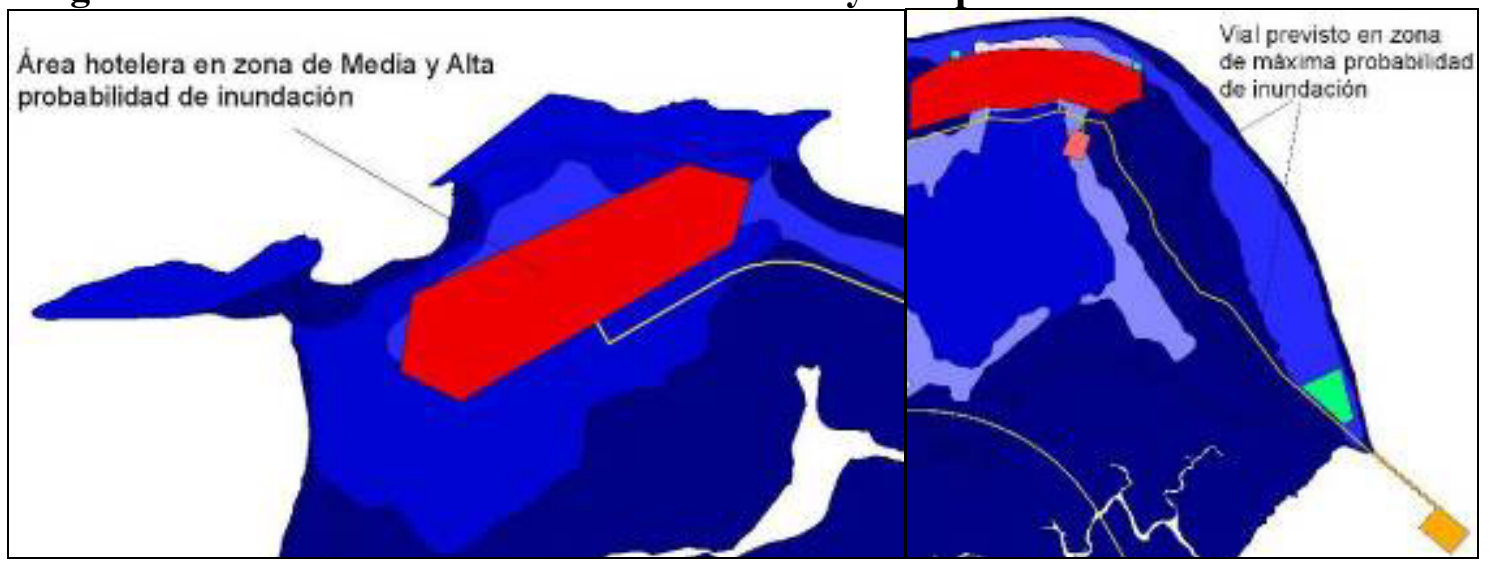

Fuente: Elaboración propia.

Valoración del estado de conservación

En la Etapa A, prácticamente la totalidad del cayo se encontraba en un estado de conservación 'Bueno' o 'Muy Bueno', debido a la poca intervención humana hasta ese momento. En la Etapa B, el oeste del cayo sufre un notable descenso en los valores.

\section{Valoración del potencial para el ecoturismo}

Como en la mayoría de los casos, las unidades más afectadas por la intervención humana -en el oeste del cayo- sufren una drástica disminución del valor del potencial para el ecoturismo entre la Etapa A y la Etapa B.

\section{Valoración de las áreas con mayor importancia ecológica}

Como en casos anteriores, la intervención humana ocasiona un gran descenso en los valores de las unidades del oeste del cayo. Destaca la alta valoración de las lagunas y de las unidades que forman parte del contacto que se produce a lo largo de todo el sur del cayo entre el manglar, las comunidades halófitas y el bosque siempreverde.

Valoración de la factibilidad constructiva en función del sustrato geológico

Lo más importante es que del "Estudio de la línea base ambiental de Cayo Santa María, escala 1:10.000" (Trujillo, 1998) se deduce que ninguna zona del cayo puede considerarse totalmente factible para construir, de ahí que todas las valoraciones tienen una tendencia negativa. En el análisis realizado para esta investigación, resultan como 'Muy poco factibles' fundamentalmente las unidades inundables y las unidades de 
mayor altura. En el primer caso, por los riesgos de encharcamientos, inundaciones, colmatación de lagunas, etc., además de la muy alta susceptibilidad del medio.

En el segundo caso, el factor limitante es la gran carsificación de las unidades más altas del cayo, lo cual dificulta la construcción (unidad 26, fundamentalmente). Para superar esta limitación, los constructores han utilizado explosivos con los que se hunde intencionadamente el firme y se evitan futuros riesgos. Este procedimiento tiene un impacto irreversible sobre las unidades de paisajes, los ecosistemas y la biodiversidad, por lo que se desaconseja totalmente.

\section{Figura 13. Unidades hoteleras y viales sobre zonas con riesgo de hundimiento del carso.}

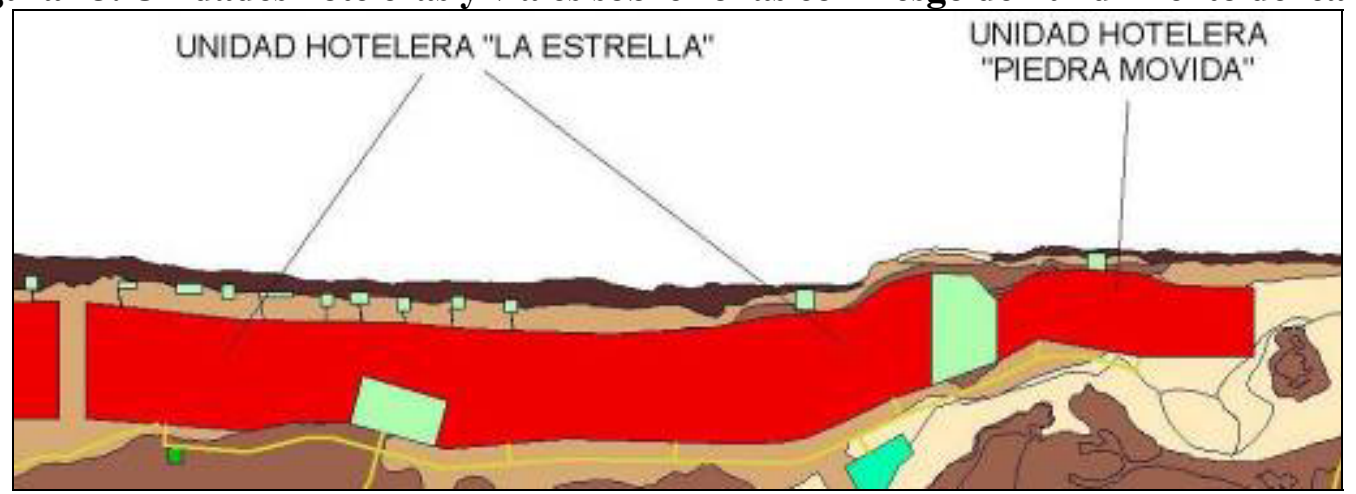

Fuente: Elaboración propia.

La unidad hotelera "La Estrella" y la unidad "Piedra movida", están previstas sobre polígonos con posible riesgo de hundimiento del carso. Lo mismo ocurre con las parcelas previstas para la parte oriental del cayo, parcialmente situadas sobre polígonos de la unidad 26 con características similares a los anteriores.

Figura 14. Unidades hoteleras y viales sobre zonas con riesgo de hundimiento del carso.

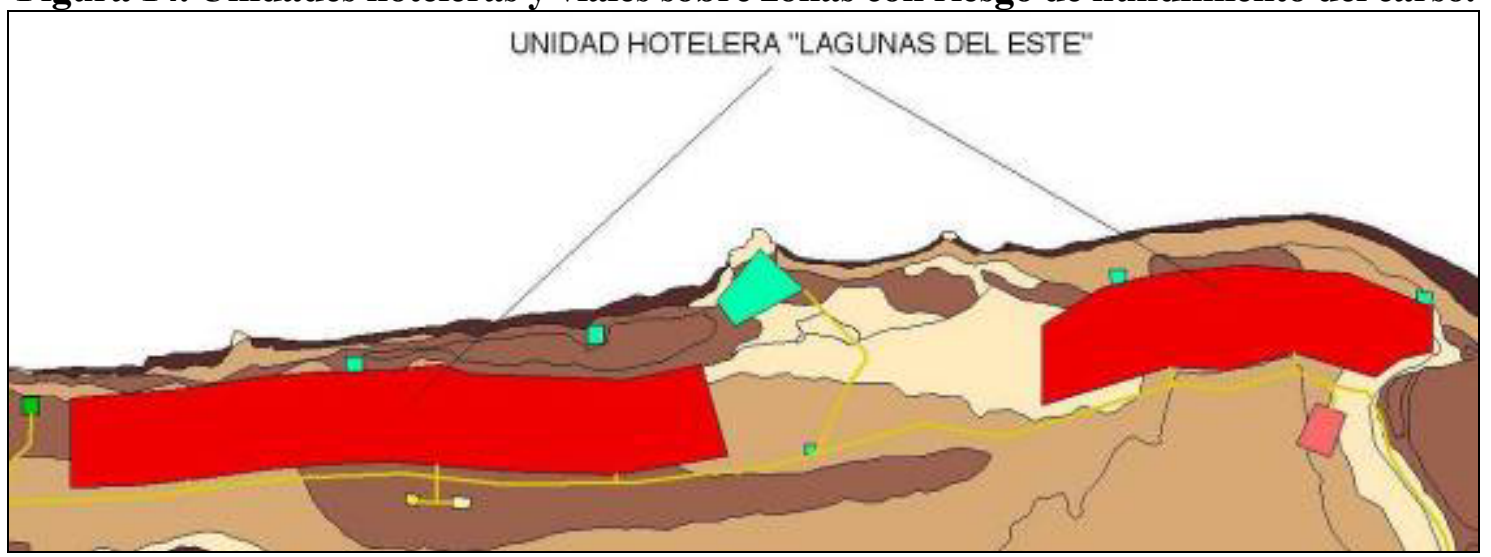

Fuente: Elaboración propia.

Por otro lado, una gran parte del cayo obtiene la valoración de 'Poco factible' (en el caso de las dunas con matorral xeromorfo, por el riesgo de erosión y la alta susceptibilidad del medio). Resulta curioso comprobar cómo las únicas unidades con valoración 'Medianamente factible' para construir, son las más bajas y por tanto con mayor tendencia a la inundación, lo cual también las desaconseja para construir según dicho factor. 
Síntesis de la valoración de las unidades de paisaje para su conservación

Etapa A: De la síntesis de todas las valoraciones realizadas a las unidades de paisaje resulta que el centro y el este del cayo presentaban una valoración 'Alta' para su conservación en la Etapa A, fundamentalmente debido a los mayores valores de biodiversidad, a un mejor estado de conservación y a un mayor potencial para el ecoturismo. El sur y el oeste presentaban una valoración 'Media'; y el resto, 'Baja'.

Figura 15. Representación de la valoración de las unidades de paisaje para su conservación (Etapa A).

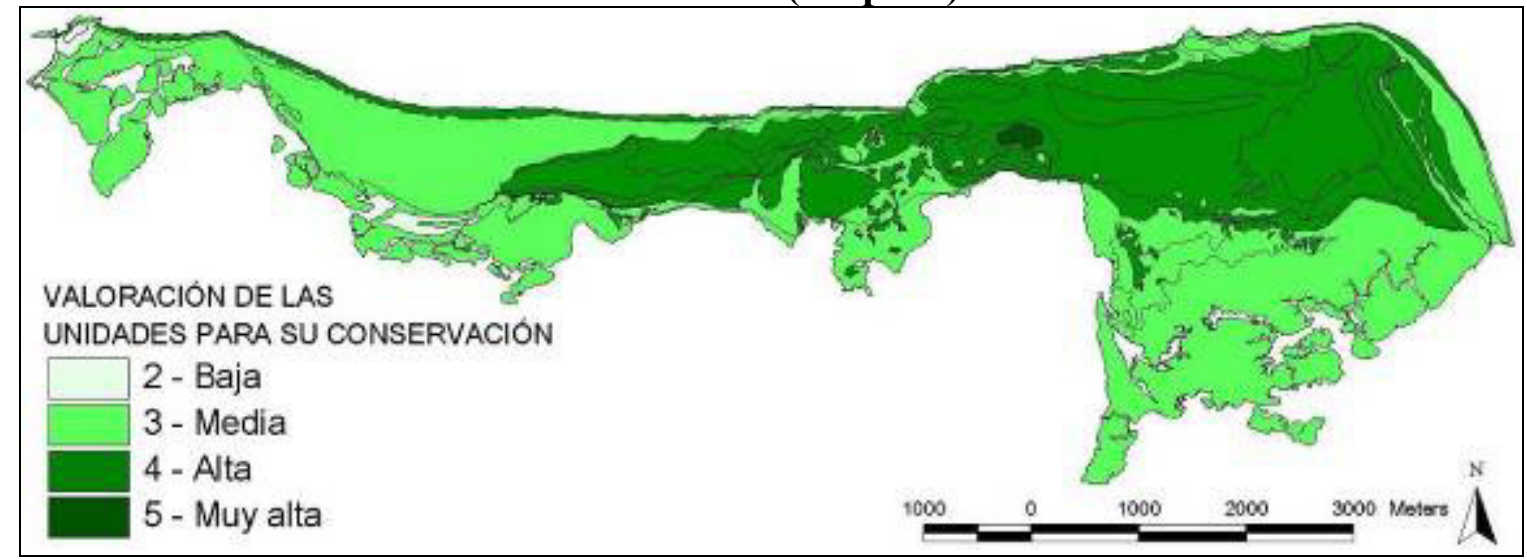

Fuente: Elaboración propia.

Etapa B: En esta etapa, la ocupación del suelo ha ocasionado que todo el oeste del cayo vea reducida su valoración hasta el nivel 'Bajo'. Algunos polígonos del centro, también muy afectados, han provocado que las unidades 23 y 26 vean asimismo reducida su valoración, de forma que gran parte del este del cayo ha obtenido la valoración 'Media'.

Figura 16. Representación de la valoración de las unidades de paisaje para su conservación (Etapa B).

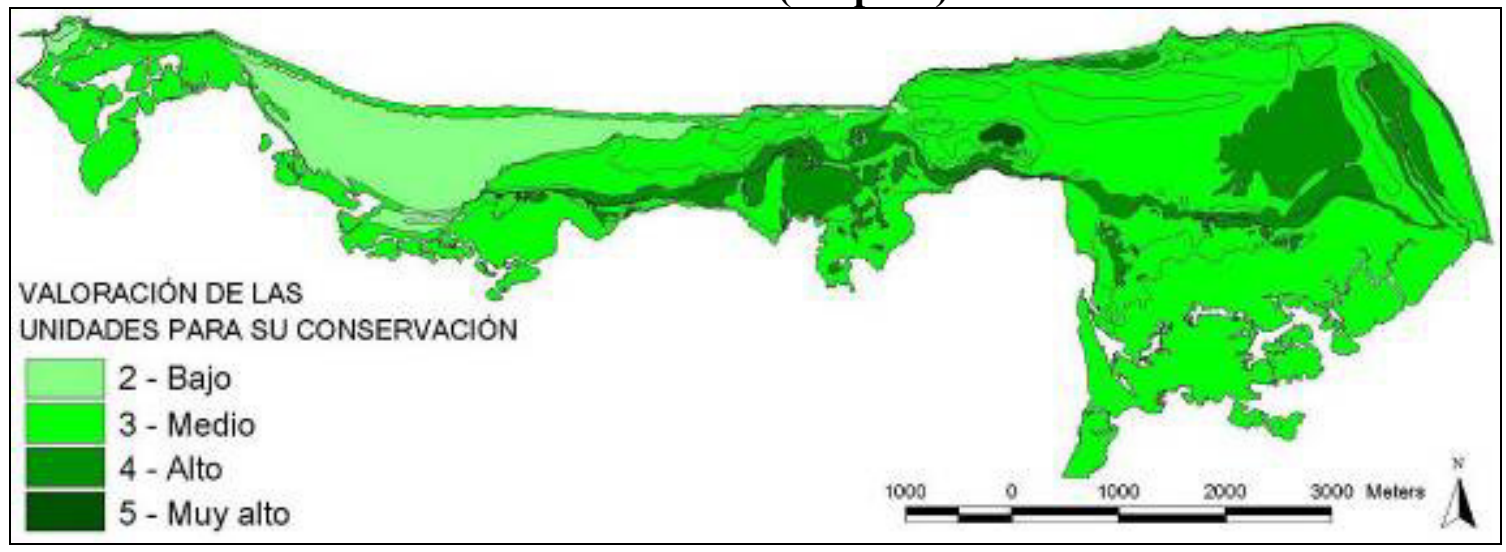

Fuente: Elaboración propia. 


\section{Valoración de los impactos ambientales sobre las unidades de paisaje}

\section{Análisis de fragmentación}

Etapa A: En esta etapa, las unidades más afectadas son la 5, 20 y 32. La primera debido a la gran cantidad de viales e instalaciones que se han construido en ella. Las otras dos, debido a la construcción del nuevo vial sur.

Etapa B: Con las nuevas construcciones y viales, se prevé que sean muchas más las áreas del cayo afectadas por una alta fragmentación, especialmente las unidades 14, 23 y 26, que adquieren el valor de fragmentación 'Muy Alto'.

\section{Pérdida de hábitat natural}

Etapa A: Las más afectadas son las unidades 5, 8, 11 y 27. Hay que señalar que la unidad 26 ha sufrido una gran pérdida de hábitat en sus dos polígonos del centro-oeste. Sin embargo, esto no se refleja en la valoración ('Baja'), puesto que la unidad todavía mantiene cuatro polígonos en el este del cayo que no han sufrido intervención alguna.

Etapa B: En esta etapa, las unidades más afectadas por la pérdida de hábitat natural se prevé que sean las unidades 13, 14, 15, 22, 23 y 26. Es reseñable el caso de la unidad 13 , la cual no suele aparecer afectada en otras valoraciones, pero que aquí llama la atención acerca de la previsión de construir un hotel sobre una superficie perilacustre (antigua laguna actualmente colmatada) con una alta tendencia a inundarse (Figura 23).

\section{Pérdida de calidad estética y sensorial}

Etapa A: Como era de esperar, la unidad más afectada por la pérdida de calidad estética y sensorial es la unidad 5. Al igual que en casos anteriores, los polígonos centrales de unidades como la 23 y la 26 , tras verse afectados, provocan una alta valoración en toda la unidad, con lo que éstas obtienen una 'Alta' pérdida de calidad estética y sensorial.

Etapa B: En la Etapa B, aumenta la pérdida de calidad sobre todo en las unidades 14, 23 y 26 , además de la unidad 32 , pues es previsible que la afección provocada por el movimiento y ruido de la marina prevista tenga un fuerte impacto sobre los manglares.

\section{Contaminación}

Etapa A: La más afectada vuelve a ser la unidad 5, junto con las unidades 8 y 11, que también han acogido construcciones de manera notable. Les siguen las unidades 14, 20 y 27 , fundamentalmente debido a la contaminación que supone el vial regional y los vehículos que por él transitan.

Etapa B: Gran parte del cayo obtiene la valoración de contaminación 'Alta' en esta etapa, pues son pocas las unidades que se libran de acoger alguna construcción o de ser atravesadas por viales. Destaca también la unidad 32, con una valoración 'Moderada', por dos razones: en primer lugar, en esta etapa es previsible que sufra con más notoriedad los efectos de los residuales vertidos a partir de las plantas de tratamiento; en segundo lugar, se prevé que los manglares también se vean afectados por el tráfico de embarcaciones que atraerá la marina. 


\section{Afecciones a la biodiversidad}

Etapa A: La unidad más afectada vuelve a ser la 5, aunque gran parte del cayo sufre una afección 'Moderada'. En el caso de las unidades con bosque siempreverde, por el alto valor de la biodiversidad que albergan. En el caso de los manglares, fundamentalmente por una alta fragmentación.

Etapa B: Con las nuevas construcciones previstas, la biodiversidad de casi todo el centro-este del cayo se verá afectada, según la valoración realizada, con nivel 'Alto'. Son pocas las áreas del cayo que quedan sin ser afectadas por viales o construcciones, pero sufren el efecto de "contagio" del valor de aquellas áreas afectadas, con lo que toda la unidad resulta con alta valoración, como en el caso de la unidad 23.

\section{Afecciones a las áreas de mayor importancia ecológica}

Etapa A: En el oeste del cayo existía una importante colonia de nidificación de torcaza cabeciblanca, hoy desaparecida, además de otros valores ecológicos importantes. Tras las primeras construcciones, esta zona resulta con una afección 'Muy alta'. Además, la afección 'Moderada' se percibe en gran parte del cayo, como por ejemplo en los manglares, que cumplen una importante labor de protección en estos espacios tan frágiles.

Etapa B: Con las construcciones previstas para esta etapa, las unidades con bosque siempreverde sufrirán un incremento en las afecciones hasta el nivel 'Alto', con los consiguientes efectos negativos para la fauna y la flora, debido a que esta formación vegetal tiene importantes funciones de hábitat y dispersión de especies.

Síntesis de la valoración de los impactos ambientales

Etapa A: En la síntesis de la valoración de impactos para esta etapa, resulta la unidad 5 con una valoración 'Muy alta'; seguida de las unidades 8 y 11, con valoración 'Alta'.

Etapa B: En esta etapa, es preocupante el incremento generalizado de las valoraciones hasta el nivel 'Alto' sobre todo en el centro-este del cayo, afectando a importantes áreas por sus valores ecológicos y de biodiversidad, como se indicó anteriormente.

Figura 17. Representación de la síntesis de la valoración de los impactos (Etapa A).

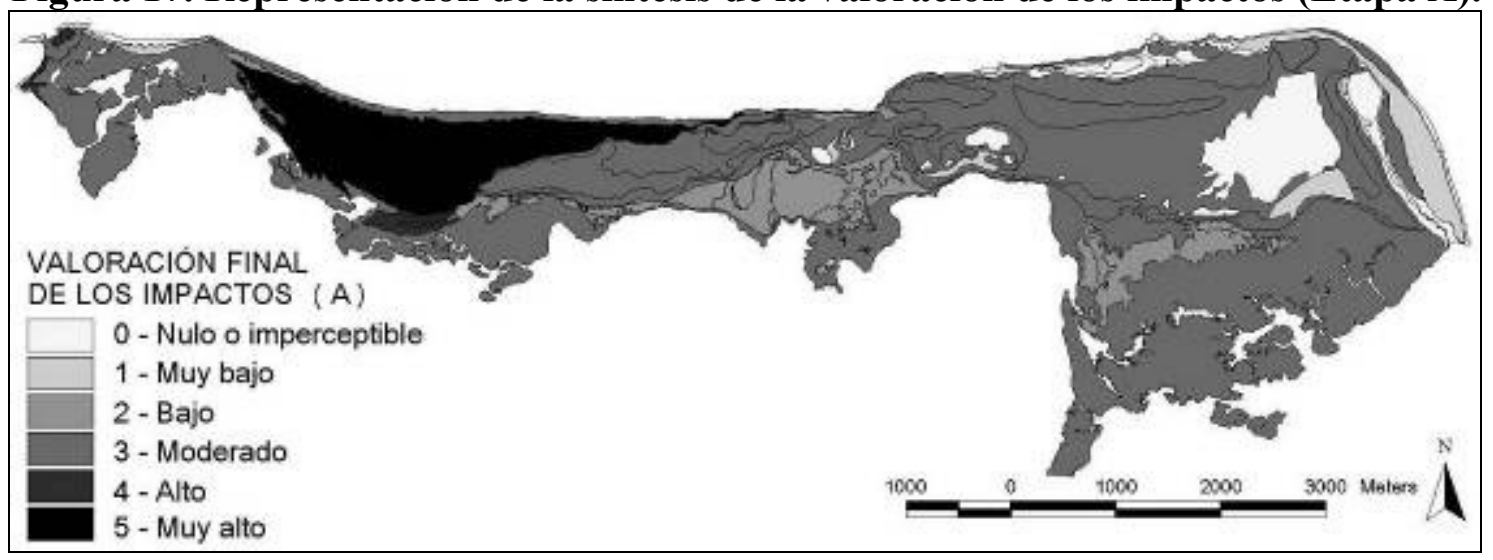

Fuente: Elaboración propia. 
Figura 18. Representación de la síntesis de la valoración de los impactos (Etapa B).

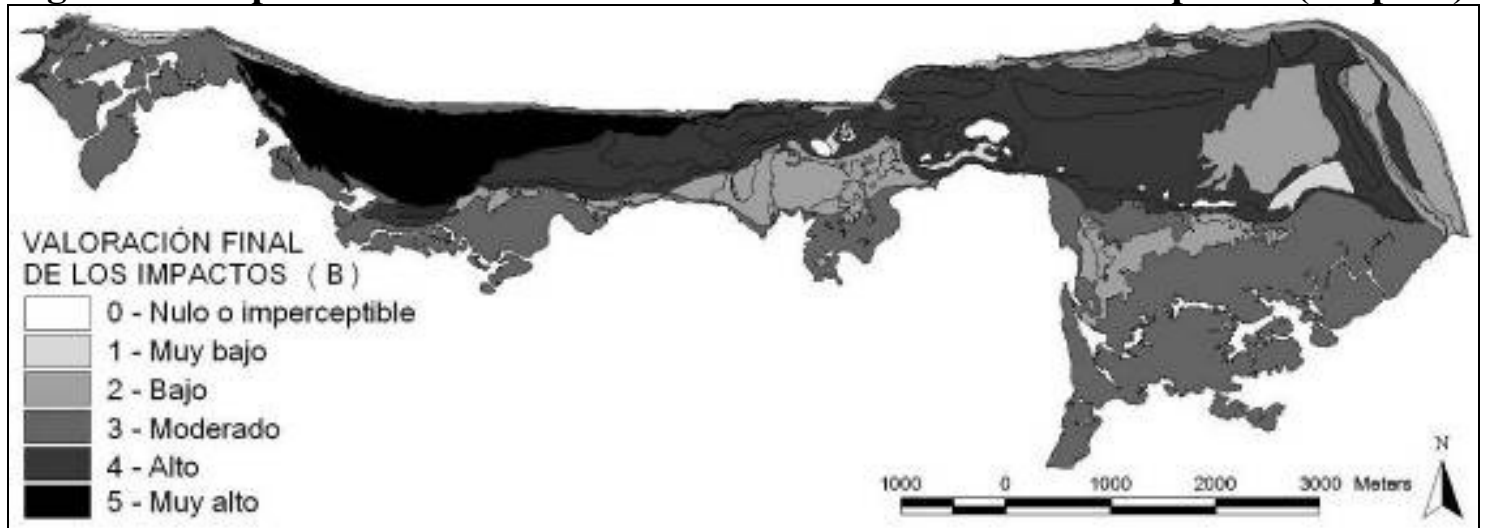

Fuente: Elaboración propia

\section{Afecciones a la sostenibilidad de las unidades de paisaje}

\section{Etapa $B$}

Del cruce entre la valoración de las unidades para su conservación y la valoración de los impactos de la Etapa A, resultan las afecciones a la sostenibilidad de las unidades de paisaje al comienzo de la Etapa B. Las más afectadas son: por un lado, la unidad 5, debido a los impactos que ha percibido; por otro lado, aparece la unidad 20, pues a pesar de no haber sufrido tantos impactos, tenía una valoración 'Alta' para su conservación.

Figura 19. Afecciones a la sostenibilidad de los paisajes naturales (Etapa B).

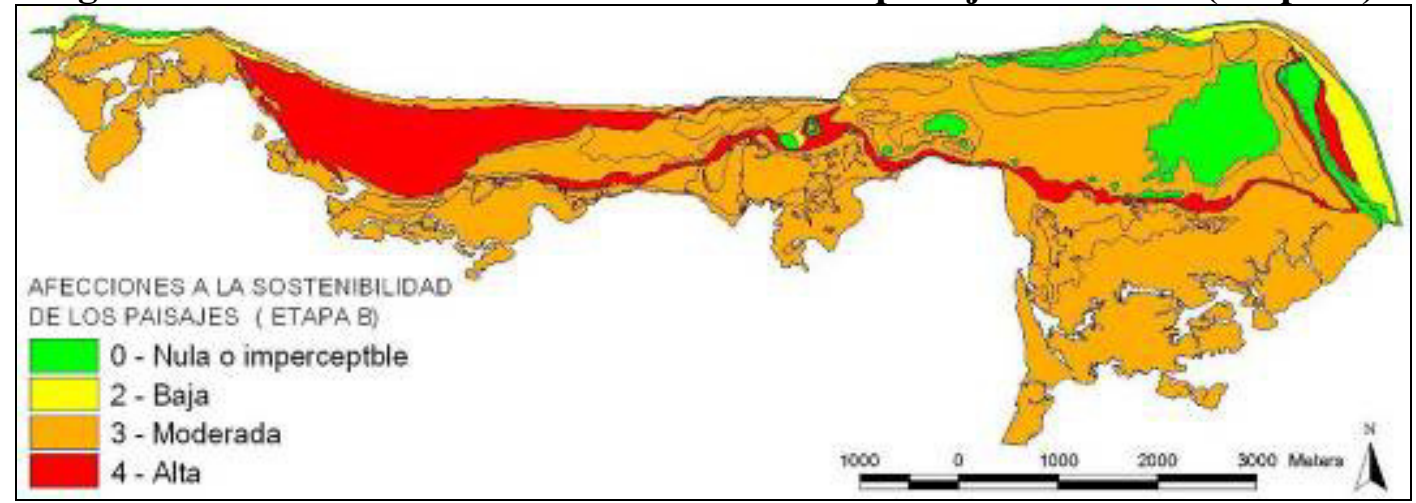

Fuente: Elaboración propia

Figura 20. Porcentaje de área según nivel de afección a la sostenibilidad (Etapa B).

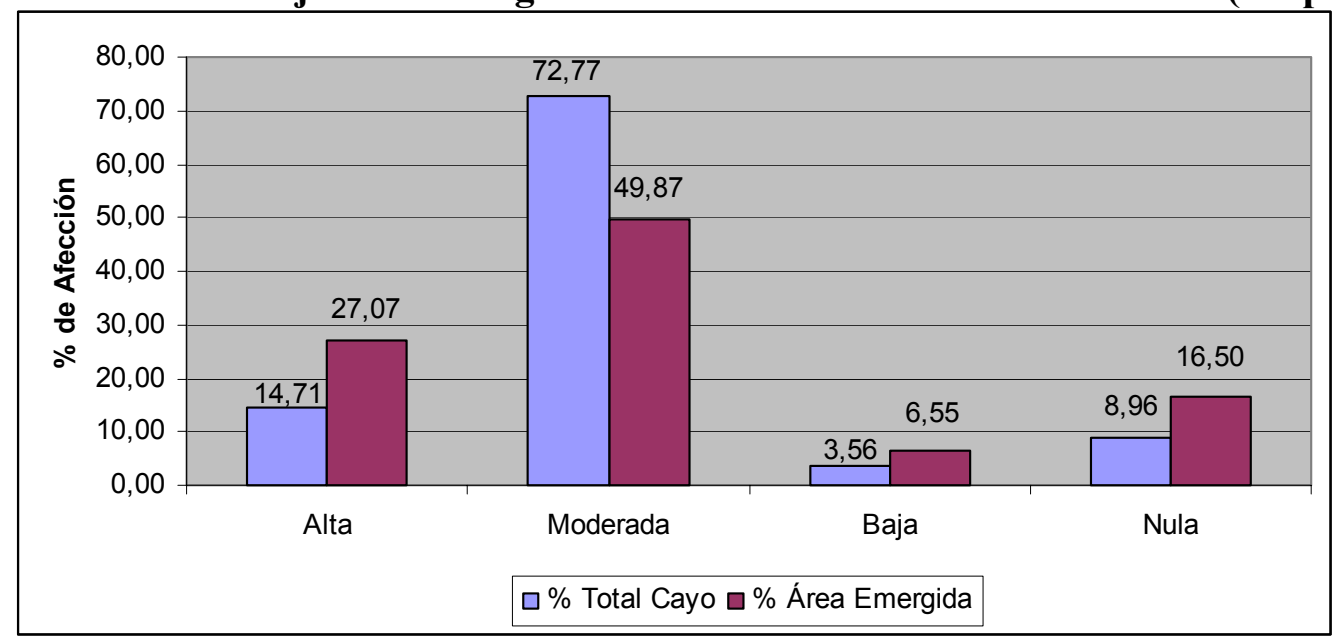

Fuente: Elaboración propia 


\section{Etapa $C$}

Si las construcciones se llevan a cabo tal como se espera, un $35,29 \%$ del cayo $(64,96 \%$ de la superficie emergida) resulta con una 'Alta' afección a la sostenibilidad de las unidades de paisajes. Esto sin tener en cuenta a la unidad 26, la cual resulta con una valoración de 3,499; es decir, en el límite de pasar a obtener la valoración 'Alta'. Si esta unidad se incluyera, los porcentajes aumentarían a $41,1 \%$ y $75,65 \%$ respectivamente.

Por otro lado, prácticamente todo el resto del cayo sufre una afección 'Moderada' $(59,15 \% ; 24,79 \%$ de la superficie emergida). Tan sólo unas pocas unidades de dunas reciben una 'Baja' afección. Pero lo más alarmante es que las unidades no afectadas representan únicamente un $0,73 \%$ del total del cayo (1,35\% de la superficie emergida). Nótese que los cambios más llamativos con respecto a la etapa anterior son: por un lado la disminución de las unidades no afectadas; y por otro, el gran aumento de las unidades con 'Alta' afección. Esto da una idea del desequilibrio que se producirá si no se toman las medidas adecuadas.

Figura 21. Afecciones a la sostenibilidad de los paisajes naturales (Etapa C).

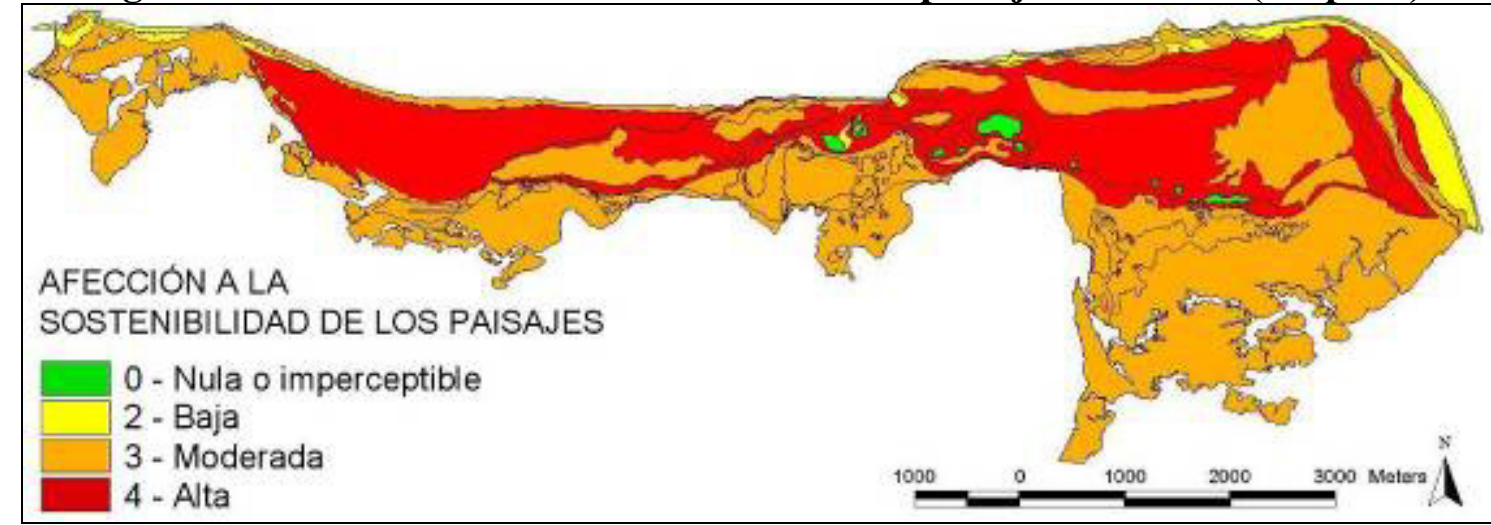

Fuente: Elaboración propia

Figura 22. Porcentaje de área según nivel de afección a la sostenibilidad (Etapa C).

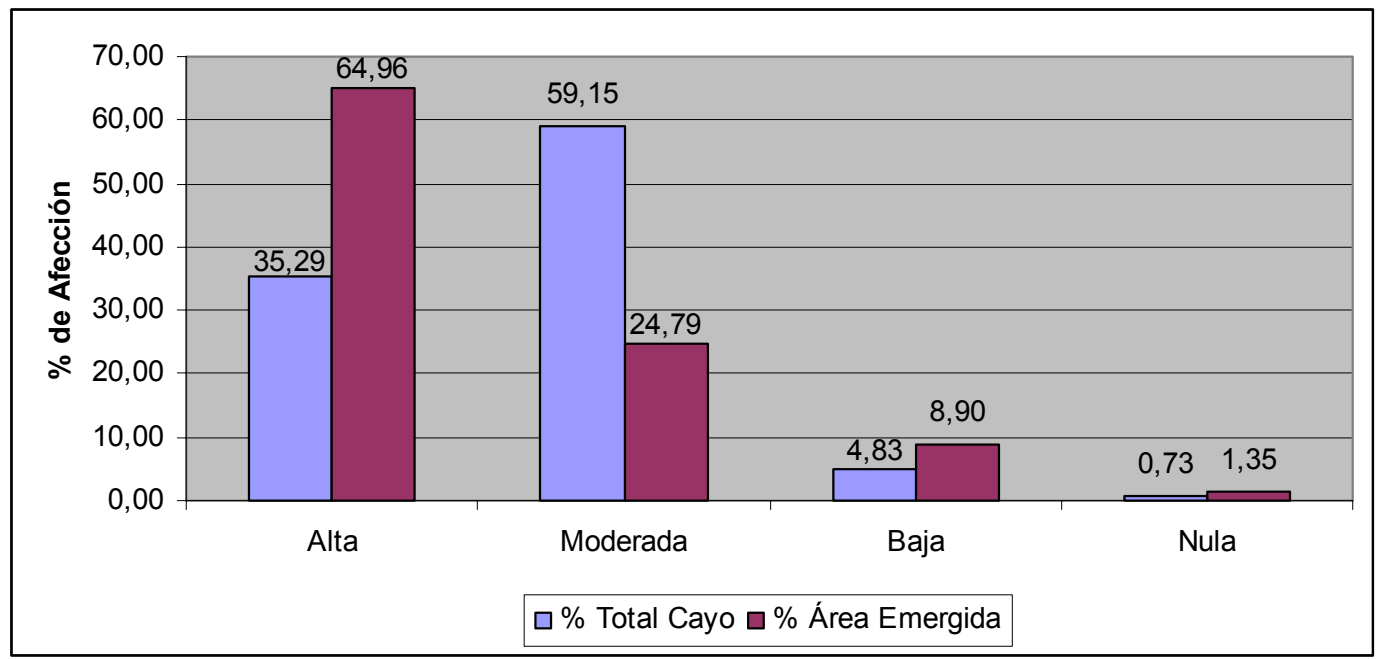

Fuente: Elaboración propia 


\section{PROPUESTA DE MEDIDAS}

\section{Etapa anterior a las construcciones}

1.1. Minimizar el impacto en el levantamiento topográfico previo a las construcciones. Limitar el número de trochas y su anchura, fundamentalmente en dirección norte-sur. No realizar trochas en la franja de protección costera. Utilizar otras alternativas: uso de GPS, Estación Total, etc.

1.2. No realizar desbroces de vegetación desmesurados, sólo en aquellos lugares donde se va a construir una instalación.

\section{Proceso de construcción de viales e instalaciones}

2.1. Establecer un plan de tratamiento de residuos en el proceso constructivo y evitar su vertimiento indiscriminado.

2.2. No utilizar maquinaria pesada en la medida de lo posible.

2.3. No utilizar detonaciones para hundir el carso, sino optar por otras soluciones menos agresivas.

2.4. Evitar cualquier tipo de construcción, incluso las más ligeras, en unidades inundables (especialmente 31, 32 y 33 ).

\section{Modelos constructivos}

3.1. Cambiar los modelos constructivos en las parcelas hoteleras.

3.2. Seguir la tendencia del primer hotel construido en el cayo: instalaciones pequeñas, más adaptadas al entorno en tamaño, materiales, formas y color.

3.3. Disminuir el número de caminos y su anchura en el interior de las parcelas hoteleras.

3.4. Eliminar y evitar las plantas exóticas en la jardinería de los hoteles, utilizar plantas autóctonas.

3.5. Establecer planes de manejo y conservación de las superficies forestales intrahoteleras.

3.6. Reducir el área de la parcela "Piedra movida", fundamentalmente hacia el este, para evitar las afecciones a la comunidad de gramíneas (unidad 19), a los manglares y laguna cercanos (unidades 21, 33 y 33), así como a las unidades de bosque siempreverde del estrechamiento del cayo (unidades 7 y 14), de una importancia crucial en el intercambio genético y la circulación de especies del cayo.

3.7. Reducir las dimensiones y área de las dos parcelas hoteleras "Lagunas de Este", para evitar las zonas con riesgo de hundimiento del carso (unidad 26), y la laguna colmatada (superficie perilacustre, unidad 13), o construir únicamente instalaciones ligeras en las zonas de mayor riesgo. Respetar el perímetro de protección del manglar (40 m) en la unidad "Lagunas del Este (oeste)". 
Figura 23. Parcelas previstas sobre zonas perilacustres y antigua laguna colmatada sin respetar el área de protección del manglar.

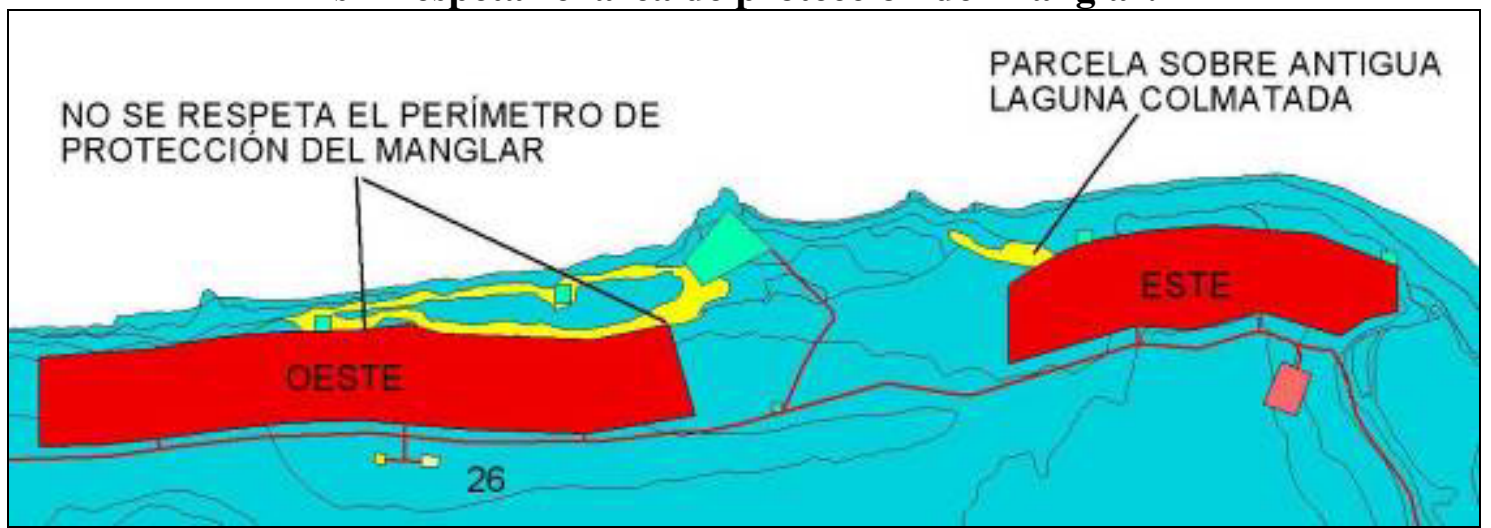

Fuente: Elaboración propia.

\section{Viales}

4.1. Limitar el número de viales, construir sólo los estrictamente necesarios.

4.2. Limitar la anchura de los viales y adaptarlos al entorno.

4.3. No construir nuevos viales no previstos, por ejemplo entre la nueva parcela hotelera "Dunas III" y las parcelas contiguas.

4.4. Descartar la construcción del vial hacia la marina internacional proyectada.

4.5. Eliminar el antiguo vial norte-sur en el este del cayo: cerrar el paso y restaurar la vegetación natural.

4.6. Eliminar el vial extra de la casa de negocios.

4.7. Descartar o desviar hacia el norte el vial que atraviesa la unidad 16.

4.8. Limitar la velocidad de circulación de los vehículos en todos los viales del cayo.

Figura 24. Detalle de los viales a eliminar o desviar.

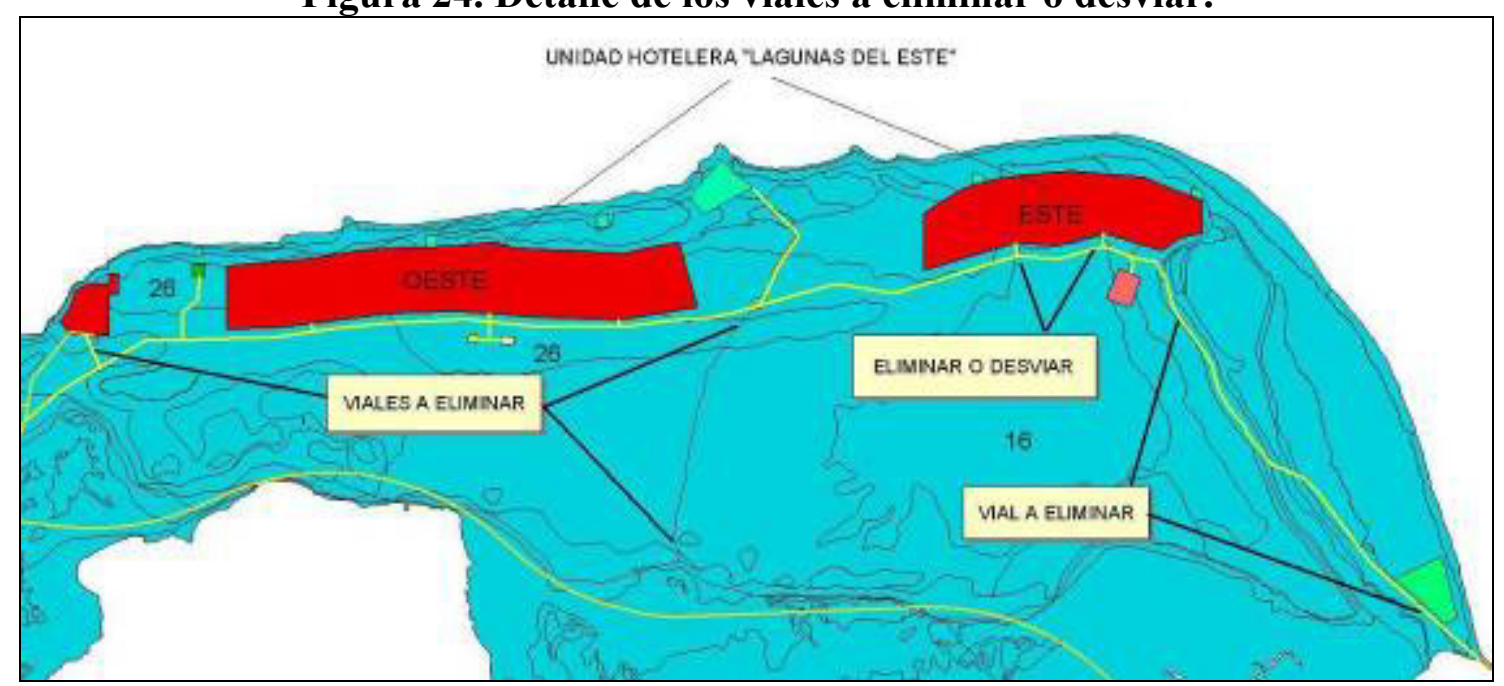

Fuente: Elaboración propia. 


\section{Plantas de tratamiento de residuales}

6.1. No abrir al público los hoteles hasta que las plantas de tratamiento de residuales estén en óptimo funcionamiento, comprobado con las auditorías pertinentes.

6.2. Establecer un plan periódico de seguimiento y evaluación de la calidad de las aguas vertidas por las plantas de tratamiento.

\section{Pasarelas y playas}

7.1. Reducir el número de pasarelas desde las parcelas hoteleras hacia las playas.

7.2. Establecer un plan de manejo y conservación de las playas del cayo.

\section{Control de vectores e insectos}

8.1. Utilizar controles biológicos de plagas en lugar de fumigaciones con productos químicos que afectan a las especies naturales del cayo.

\section{Servicios extrahoteleros}

9.1. Reducir el número de ranchones y bares de playa, así como el de las sombrillas.

9.2. Reducir el área de los servicios extrahoteleros previstos para el noreste: alejarla del área de protección del manglar y cuidar en su construcción de no afectar especies amenazadas como Isocarpa glabrata o Pilosocereus robinii.

9.3. Eliminar los servicios extrahoteleros del este de la parcela "Lagunas del Este (este)", con el fin de concentrar la actividad recreativa de los huéspedes hacia el norte y alejándola en la medida de lo posible de la Playa Las Gaviotas.

9.4. Descartar definitivamente la construcción de los servicios extrahoteleros previstos al sur de la nueva parcela en construcción "Dunas III".

9.5. Descartar la construcción de los servicios extrahoteleros sobre la superficie perilacustre del norte del cayo (Figura 25) o buscar una ubicación alternativa.

Figura 25. Propuestas para los servicios extrahoteleros.

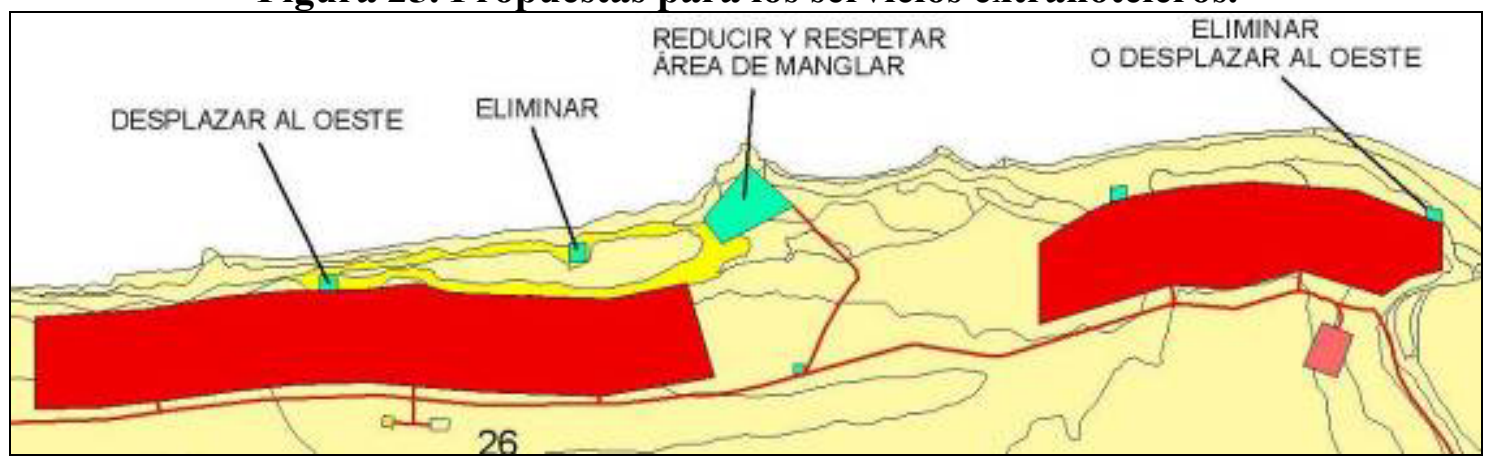

Fuente: Elaboración propia.

\section{Marina}

10.1. Descartar definitivamente la construcción de la marina internacional prevista en el sureste del cayo, entre otras cosas, por el dragado de materiales con un elevadísimo coste económico y ecológico. Descartar la construcción de las oficinas de la marina y su vial de acceso, previsto por una zona de máxima probabilidad de inundación y de mínima factibilidad constructiva (superficie perilacustre de la laguna salada del este). 


\section{CONCLUSIONES}

1. Antes de la asimilación turística, Cayo Santa María era un espacio con un estado de conservación envidiable, alta riqueza y diversidad de especies, playas de gran calidad escénica y altos potenciales para el ecoturismo. Tras el comienzo de las construcciones y hasta la etapa actual, las unidades de paisaje del centro y oeste se han visto afectadas en todos los factores analizados. Tan sólo algunas áreas del este del cayo se conservan aún casi intactas. Son éstas las áreas que siempre han atesorado los mayores valores.

2. Los impactos ambientales percibidos hasta la fecha han afectado principalmente al centro-oeste del cayo, siendo la fragmentación de las unidades de paisaje y la pérdida de hábitat natural los factores que más están afectando desde el punto de vista espacial. Otros factores como la contaminación, la pérdida de calidad estética, la introducción de especies, etc., son igualmente preocupantes.

3. En general, todo esto es consecuencia de la aplicación de un modelo de desarrollo sobredimensionado para un territorio tan pequeño y frágil, basado fundamentalmente en: la tendencia "sol y playa"; modelos constructivos importados, poco adaptados al entorno; viales sobredimensionados; planes de construcción precipitados y sin la necesaria evaluación de los impactos ambientales; excesiva ocupación del suelo y excesivo número de habitaciones previstas, etc.

4. Como consecuencia, en la actualidad todo el oeste del cayo sufre una alta afección a la sostenibilidad de las unidades de paisaje. Si el modelo se sigue aplicando de esta manera, es previsible que al final de las construcciones se haya afectado de forma crítica también la mitad oriental del cayo, sumando un área de más de las $2 / 3$ partes de la superficie emergida, incluyendo algunas de las unidades de paisaje que atesoran los mayores valores.

5. Para revertir esta tendencia, sobre todo en la parte oriental del cayo, sería necesario, entre otras cosas: reducir el número de habitaciones previstas; descartar los modelos importados y construir instalaciones más pequeñas, integradas y adaptadas al entorno, teniendo en cuenta las condiciones geológicas, geomorfológicas, edafológicas, de cobertura vegetal, etc., de las unidades de paisaje, antes de comenzar a construir; minimizar los impactos en los levantamientos topográficos; adaptar las dimensiones y anchura de los viales al reducido espacio del cayo; realizar las correspondientes evaluaciones de impacto ambiental antes de comenzar a construir; diversificar el modelo turístico propuesto, hacia el ecoturismo y otras alternativas más compatibles con la conservación de la naturaleza; etc. 


\section{BIBLIOGRAFÍA}

Academia de Ciencias de Cuba (ACC). Génesis y clasificación de los suelos de Cuba. La Habana: ACC, 1973.

Academia de Ciencias de Cuba (ACC). Nuevo Atlas Nacional de Cuba. La Habana: ACC, 1989.

Academia de Ciencias de Cuba (ACC). Estudio de los grupos insulares y zonas litorales del archipiélago cubano con fines turísticos. Cayos Francés, Cobos, Las Brujas, Ensenachos y Santa María. La Habana: Editorial Científico Técnica, 1990.

ACEVEDO, P. Análisis de los paisajes insulares del Archipiélago Sabana - Camagüey. La Habana: Universidad de la Habana, 1997. 135 p.

ARIAS, A. Ecología de las comunidades de lagartos de Cayo Santa María, Villa Clara, Cuba. Pinar del Río (Cuba): Universidad de Pinar del Río, 2009. 181 p.

ARIAS, A. et al. Relaciones entre las comunidades de aves, reptiles e insectos con la estructura de la vegetación en Cayo Santa María. Santa Clara (Cuba): CESAM-Villa Clara, 2008.

CESAM. Identificación y evaluación de los impactos ambientales provocados por el desarrollo del turismo en los cayos del Noreste de Villa Clara. Santa Clara (Cuba): Centro de Estudios y Servicios Ambientales de Villa Clara (CESAM), 2009.

CITMA. Monografía del Proyecto GEF/PNUD Sabana-Camagüey 2000-2004. Santa Clara (Cuba): CESAM (Ministerio de Ciencia, Tecnología y Medio Ambiente), 2006.

CITMA. Programa de Manejo Integrado Zona Especial Este de Villa Clara. Santa Clara (Cuba): CITMA-Villa Clara, 2008.

DPPFVC. Actualización del Plan General del Polo Turístico de Cayo Santa María. Santa Clara (Cuba): Direc. Provincial de Planificación Física de Villa Clara (IPF), 2010.

FAO. Departamento de Montes. Los árboles fuera del bosque. [En línea. Acceso libre]. $<$ http://www.fao.org/docrep/005/y2328s/y2328s26.htm\#TopOfPage>. [Diciembre 2010].

GOOGLE. Google Earth 5.2. [En línea. Acceso libre]. Aplicación. Imágenes de 2006. $<\mathrm{http}$ ://www.google.com/intl/es/earth/index.html $>$. [Febrero de 2010].

Instituto de Planificación Física (IPF). Plan de Ordenamiento Territorial. Cayería Noreste de Villa Clara. Santa Clara (Cuba): IPF, 2004. 22 p.

La O, J.A. Diagnóstico Geoecológico para el turismo en el sector Bahía de Vita-Bahía de Samá, Holguín. La Habana: Universidad de La Habana, 2004.

MATEO, J.M. Geografia de los paisajes. Primera parte: paisajes naturales. La Habana: Universidad de La Habana (Facultad de Geografía), 2002.

MATEO, J.M. Los caminos para el cambio. La incorporación de la sustentabilidad ambiental al proceso de desarrollo. La Habana: Universidad de La Habana, 2003. 
MATEO, J.M. Geografia de los paisajes. Segunda parte: paisajes culturales. La Habana: Universidad de La Habana (Facultad de Geografía), 2007a.

MATEO, J.M. Aportes para la formulación de una teoría geográfica de la sostenibilidad ambiental. La Habana: Universidad de La Habana (Facultad de Geografía), 2007b. 196 p.

MATEO, J.M.; Da SILVA, E.V.; BRITO, A.P. Geoecologia das Paisagens. Fortaleza (Brasil): UFC Edições, 2007. 222 p.

NOA, A., CASTAÑEDA, I.; y MATOS, J. Flora y Vegetación de Cayo Santa María (Archipiélago Sabana-Camagüey). Revista Jardín Botánico Nacional, 2001, no 22 (1), p. 67-84.

ORTEGA, F. Contribución a la clasificación de los suelos de las ciénagas cubanas. Ciencias de la Agricultura, 1980, nº 6, p. 63-86.

PICHARDO, L.O. Factibilidad Ambiental en la localización de obras para el turismo en Cayo Santa María. La Habana: Universidad de La Habana, 2003.

PRIEGO, A. et al. Propuesta para la generación semiautomatizada de unidades de paisajes. Fundamentos y métodos. México, D.F.: Universidad Nacional Autónoma de México (Centro de Investigaciones en Geografía Ambiental), 2008.

PRIEGO, A.; ISUNZA, E. Cartografia del Paisaje. Morelia (México): Universidad Autónoma de México, 2010.

REAL ACADEMIA ESPAÑOLA DE LA LENGUA. Diccionario de la lengua española. [En línea. Acceso libre]. 22a Edición. $<$ http://www.rae.es $>$. [Diciembre, 2010].

STRAHLER, A.N.; STRAHLER, A.H. Geografía Física. Barcelona: Ed. Omega, 1997.

TRIANA, M. et al. Plan de Manejo del Área Protegida de Recursos Manejados "Cayería Noreste de Villa Clara". Santa Clara (Cuba): Empresa Nacional para la Protección de la Flora y la Fauna (ENPFF), 1998. 80 p.

TRIANA, M. Planificación Ambiental Turística para el Uso Sostenible del Área Marina Protegida Refugio de Fauna "Santa María". Villa Clara, Cuba. Santa Clara (Cuba): Universidad Central "Marta Abreu" de Las Villas, 2009.

TRUJILLO, H. Geomorfología. En GEOCUBA. Estudio de Línea Base Ambiental de Cayo Santa María. Santa Clara (Cuba): GEOCUBA, 1998.

TRUJILlO, H.; LAMAR, J. Riesgos de penetraciones del mar en la cayería del nordeste de Villa Clara. Santa Clara (Cuba): GEOCUBA, 2007. 9 p.

ULlOA, D.R. Geoecología del occidente de Cayo Santa María. La Habana: Universidad de La Habana (Facultad de Geografía), 2000.

YERAS, J.I. Estudio Estratégico Ambiental del Plan de Desarrollo de Cayo Santa María. Matanzas (Cuba): Universidad de Matanzas "Camilo Cienfuegos" (Facultad de Ingeniería Química y Mecánica), 2005. 


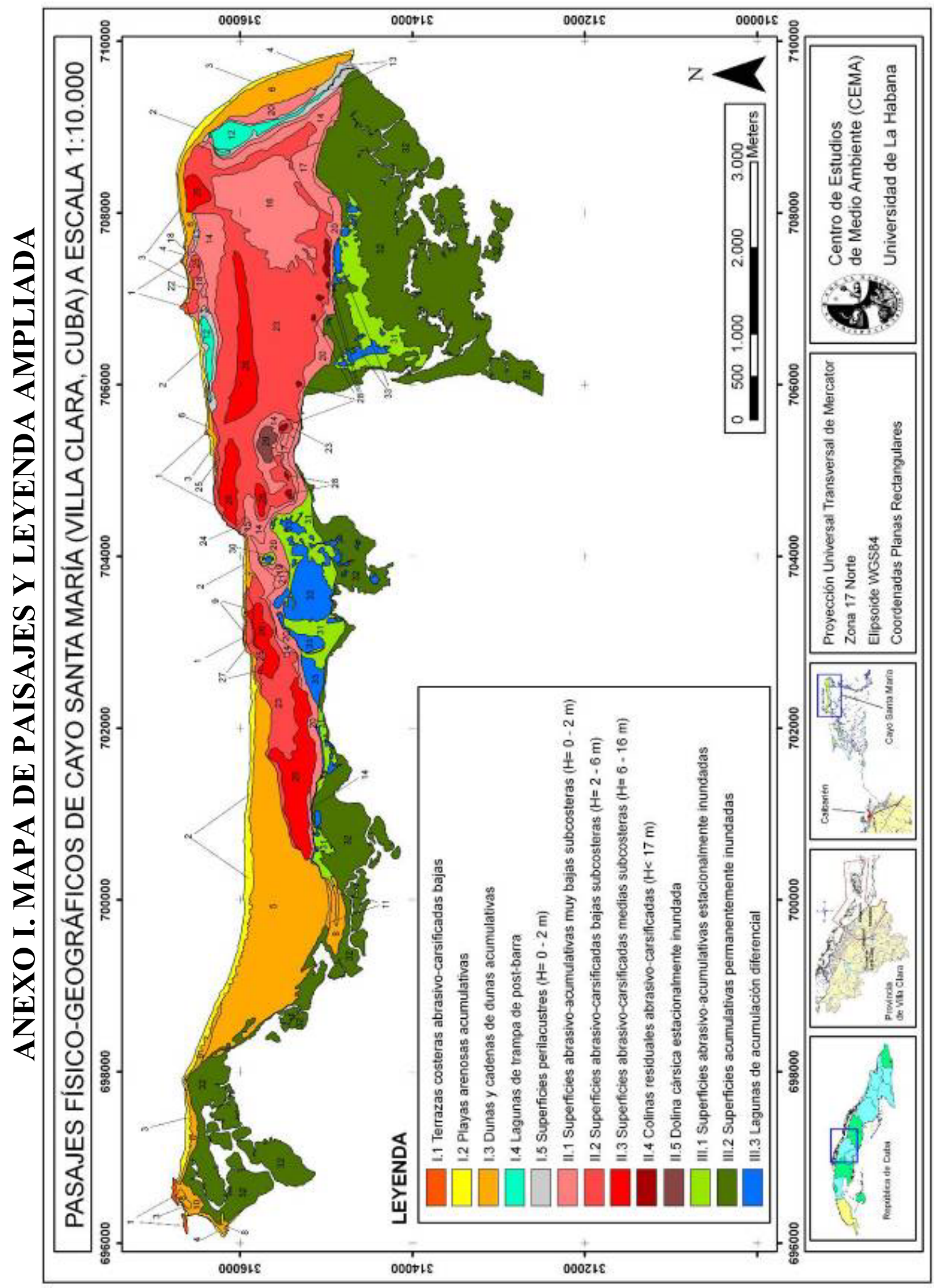




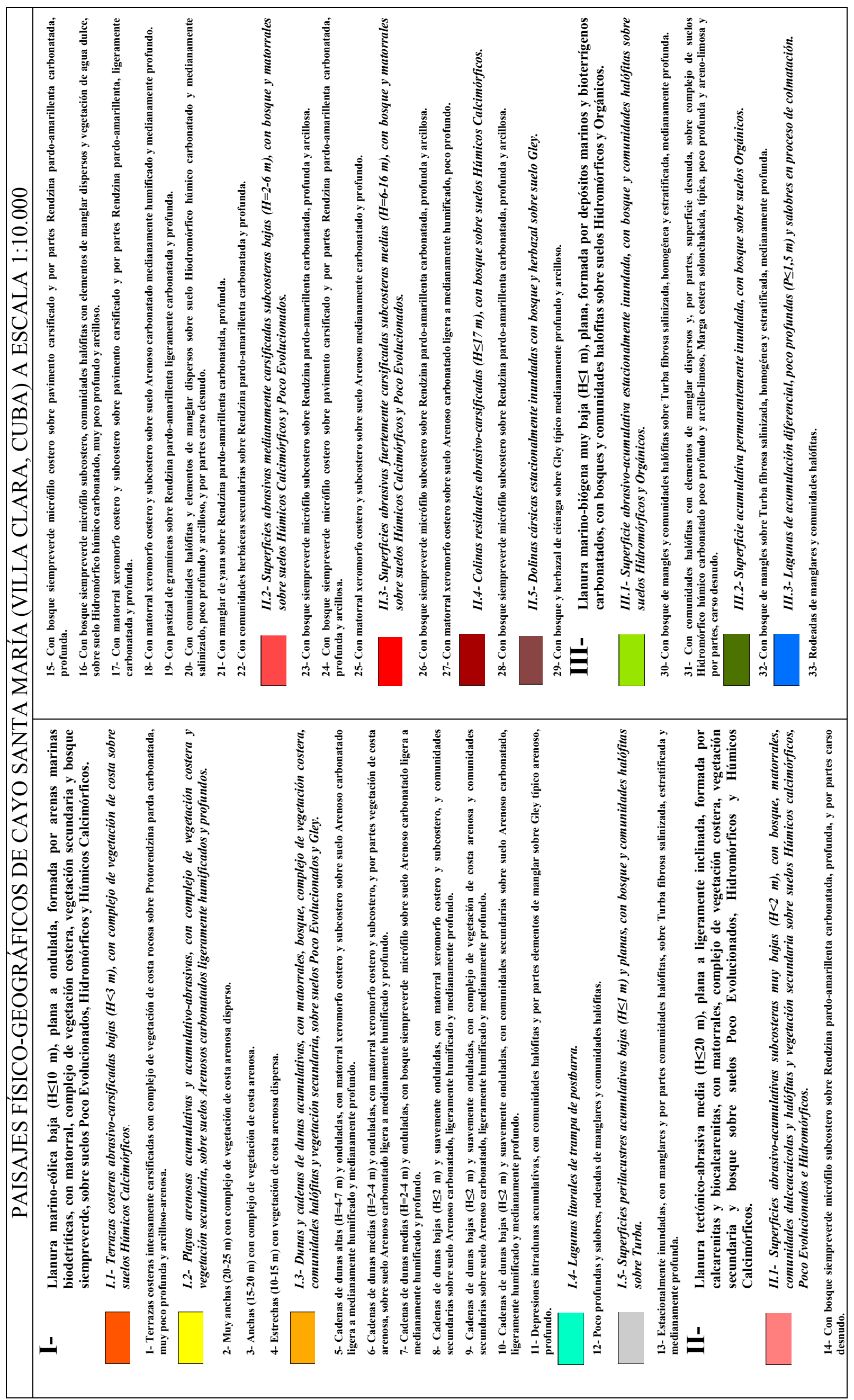




\section{GLOSARIO}

Afección: "Impresión que hace algo en otra cosa, causando en ella alteración o mudanza" (RAE, 2010).

Carso (o karst): "Paisaje o tipo de topografia dominada por elementos producidos por la disolución caliza, y que representa sistemas de cavernas subterráneas" (Strahler, 1997). Se considera, por tanto, 'carsificación' al proceso de formación del carso.

Cayería: "Conjunto de cayos" (RAE, 2010).

Cayo: "Isla rasa, arenosa, frecuentemente anegadiza y cubierta en gran parte de mangle, muy común en el Mar de las Antillas y en el Golfo de México" (RAE, 2010).

Impacto Ambiental: Según Vicente Conesa (1997), un impacto ambiental es una "relación dialéctica entre los cambios, efectos y consecuencias que ocurren en un sistema ambiental, como resultado de la acción ejercida por una determinada fuerza sobre el mismo" (Conesa, 1997; en Mateo, 2008; y en Yeras, 2005). En este caso, el sistema ambiental está constituido por cada una de las unidades inferiores de paisaje (subcomarcas).

Ocupación del suelo: "Se refiere a la cobertura física observable en el suelo por técnicas de levantamientos de campo o por teledetección. Comprende la vegetación (natural/espontánea y cultivada) y la ordenación del territorio y el hábitat (edificios, carreteras, etc.) que ocupan la superficie de la tierra, así como la hidrografía y las superficies glaciares, rocosas y arenosas" (FAO, 2010).

Paisaje Natural (o Paisaje Físico-Geográfico): “Área de la superficie terrestre de cualquier dimensión, en cuyos límites los diferentes componentes naturales (la estructura geológica incluyendo la litología, el relieve, el clima, las aguas, los suelos, la vegetación y el mundo animal) se encuentran en estado natural" (Timashev, 1999; en Mateo, 2002). Por extensión, puede utilizarse el término "paisaje natural" en referencia a unidades de paisaje constituidas únicamente por componentes naturales (litología, relieve, suelos, etc.), y ningún componente socio-económico, diferenciándose así de los "paisajes culturales"; todo ello siempre de acuerdo a los planteamientos de la Geografía de los Paisajes (Mateo, 2007a).

Sostenibilidad de los Paisajes Naturales: "Una situación de los paisajes naturales en la que a corto, mediano y largo plazo perduren las características del estado ambiental y la productividad óptima garantizados por la permanencia de sus soportes estructurales, funcionales, evolutivos y relacionales" (Mateo et al., 2007).

Subcomarcas: Son las unidades inferiores de paisaje utilizadas para los análisis en este estudio. En el mapa de paisajes existen tres niveles: 1) Localidades, o unidades superiores (representadas sólo con números romanos); 2) Comarcas, o unidades intermedias (representadas con números romanos y números naturales; y 3) Subcomarcas, o unidades inferiores (representadas sólo con números naturales).

Susceptible: Capaz de recibir modificación o impresión (RAE, 2010).

Trocha: Vereda o camino angosto y excusado, o que sirve de atajo para ir a una parte. Camino abierto en la maleza (RAE, 2010). 